\title{
Effects of drugs on mucus clearance
}

\author{
E. Houtmeyers, R. Gosselink, G. Gayan-Ramirez, M. Decramer
}

Effects of drugs on mucus clearance. E. Houtmeyers, R. Gosselink, G. Gayan-Ramirez, M. Decramer. (C) ERS Journals Ltd 1999.

ABSTRACT: Mucociliary clearance (MCC), the process in which airway mucus together with substances trapped within are moved out of the lungs, is an important defence mechanism of the human body. Drugs may alter this process, such that it is necessary to know the effect of the drugs on MCC. Indeed, agents stimulating MCC may be used therapeutically in respiratory medicine, especially in patients suspected of having an impairment of their mucociliary transport system. In contrast, caution should be taken with drugs depressing MCC as an undesired side-effect, independently of their therapeutic indication. Since cough clearance (CC) serves as a back-up system when MCC fails, the influence of drugs must be examined not only on MCC but also on CC. Ultimately, the clinical repercussions of alterations in mucus transport induced by drug administration must be studied.

Tertiary ammonium compounds (anticholinergics), aspirin, anaesthetic agents and benzodiazepines have been shown to be capable of depressing the mucociliary transport system. Cholinergics, methylxanthines, sodium cromoglycate, hypertonic saline, saline as well as water aerosol have been shown to increase MCC. Adrenergic antagonists, guaifenesin, $S$-carboxymethylcysteine, sodium 2-mercapto-ethane sulphonate and frusemide have been reported not to alter the mucociliary transport significantly. Amiloride, uridine 5'-triphosphate (UTP), quaternary ammonium compounds (anticholinergics), adrenergic agonists, corticosteroids, recombinant human deoxyribonuclease (rhDNase), $\mathrm{N}$-acetylcysteine, bromhexine and ambroxol have been reported either not to change or to augment MCC. Indirect data suggest that surfactant as well as antibiotics may improve the mucociliary transport system.

As for the influence of drugs on $\mathrm{CC}$, amiloride and rhDNase have been demonstrated to increase the effectiveness of cough. A trend towards an improved $\mathrm{C} C$ was noted after treatment with adrenergic agonists. The anticholinergic agent ipratropium bromide, which is a quaternary ammonium compound, has been suggested to decrease $\mathrm{CC}$ significantly. Bromhexine, ambroxol and neutral saline seemed not to alter CC, either positively or negatively.

Finally, treatment with either amiloride, recombinant human deoxyribonuclease, bromhexine, ambroxol, $\mathrm{N}$-acetylcysteine, $\mathrm{S}$-carboxymethylcysteine or hypertonic saline has been suggested as a possible cause of clinical improvement in patients, such as the experience of dyspnoea, the case of expectoration or the frequency of infective exacerbations. Other agents did not show a clinical benefit. Eur Respir J 1999; 14: 452-467.
Respiratory Muscle Research Unit, Laboratory of Pneumology and Respiratory Division, Faculty of Physical Education and Physiotherapy, Katholieke Universiteit Leuven, Leuven, Belgium.

Correspondence: M. Decramer

Respiratory Division

University Hospital

Herestraat 49

B-3000 Leuven

Belgium

Fax: 3216347126

Keywords: Clearance

disease

drugs

health

mucus

transport

Received: December 151998

Accepted after revision December 171998

Suppported by the "Fonds voor Wetenschappelijk Onderzoek-Vlaanderent" of which G. Gayan-Ramirez is a fellow.
Mucociliary clearance (MCC) is an important hostdefence mechanism. Cellular debris as well as inhaled infectious and toxic particles deposited on the airway mucus, are moved cephalad on the mucociliary escalator. At the end, the mucus together with the substances trapped within are swallowed or coughed up.

A retardation in mucociliary transport may lead to mucus retention for example, a condition which predisposes to bacterial colonization and may finally result in pneumonia. MCC is reported to be impaired in certain diseases, such as chronic bronchitis, cystic fibrosis (CF) and asthma. Drugs are frequently prescribed to these patients. Mostly, these drugs are administered in order to relieve respiratory complaints, such as dyspnoea and bronchospasm. Some of these drugs, however, are claimed to influence MCC. Since MCC plays an important role in the human defence mechanism, the influence on MCC of drugs administered to patients with respiratory disorders must be examined. Moreover, it is necessary to examine the influence of a given drug in a specific disease, since the underlying mechanism impairing MCC may differ from one illness to another.

Previous articles in this Series: No. 1. E. Houtmeyers, R. Gosselink, G. Gayan-Ramirez, M. Decramer. Regulation of mucociliary clearance in health and disease. Eur Respir J 1999; 13: 1177-1188. No. 2. C.P. van der Schans, D.S. Postma, G.H. Koëter, B.K. Rubin. Physiotherapy and bronchial mucus transport. Eur Respir $J$ 1999; 13: 1477-1486.

Unfortunately, B. Webber was erroneously not included as one of the editors on the two previous articles in this series. 
When the MCC mechanism is impaired, cough serves as a back-up system [1]. Indeed, an increased amount of secretion is necessary in order to make voluntary cough effective in clearing the airways [2]. Consequently, it is important to study not only the influence of drugs on MCC but also on cough clearance (CC), especially since $\mathrm{CC}$ becomes more important in patients with mucus clearance disorders.

The knowledge of the influence of a specific drug on mucus clearance may lead to a better therapeutic use of such medication. Indeed, if an agent is known to increase mucus clearance, it can be used for the treatment of mucus clearance disorders. Additionally, such drugs may be prescribed for other therapeutic purposes since an increase in mucus clearance can only be considered as positive. Conversely, the decrease in mucus clearance caused by a therapeutic agent may be considered an undesired sideeffect of the medication, especially in patients suspected of having mucus clearance impairment. Possibly, this agent can be replaced by another drug which has the same therapeutic action but does not depress mucus clearance. Finally, there are drugs that do not affect mucus clearance. These agents can therefore be administered safely as therapeutic agents to patients whatever their disease.

After evaluating the effect of a drug on MCC and CC, the question still remains as to whether these alterations in mucus transport caused by a specific agent, are of clinical significance for the patient. For example, does the risk for developing a pneumonia decrease after the administration of a certain drug? Are symptoms, such as dyspnoea and difficulty in expectoration, improved after drug treatment? The clinical benefit is ultimately the most important reason for a physician to prescribe a drug to a patient as well as for the patient to take the medication.

In this overview, the effects of various drugs on the mucociliary transport system as well as on different components of this mechanism, such as ciliary beating frequency $(\mathrm{CBF})$, mucus production and rheological properties have been evaluated. Alterations in $\mathrm{CC}$ are also discussed as well as the clinical benefit observed after drug admi-

a)

Airway lumen

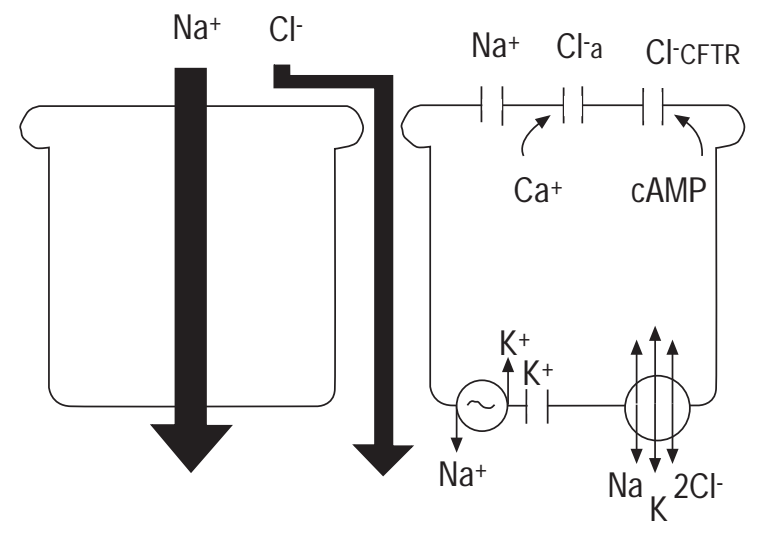

Submucosa nistration in patients. The attention is mainly focused on human studies examining the influence of medication on the mucus transport system. A database was compiled by locating articles published over the last $25 \mathrm{yrs}$ from a computer search using the Medline and Winspirs online literature databases, by scanning relevant journals and by cross-referencing various articles and reviews.

\section{Amiloride and uridine 5'-triphosphate}

Amiloride, a $\mathrm{Na}^{+}$channel blocker, and uridine 5'-triphosphate (UTP), which is known to induce $\mathrm{Cl}^{-}$secretion, modulate the disturbed ion (and liquid) transport observed across the airway epithelium in CF. Figure 1 compares the ion flow across the airway epithelium in normal subjects with that of CF patients. It clearly demonstrates the two defects in ion transport across the airway epithelium in CF patients, namely an excessive $\mathrm{Na}^{+}$(liquid) absorption and a defective cyclic adenosine monophosphate (cAMP)dependent $\mathrm{Cl}^{-}$(liquid) secretion. These genetic defects lead to abnormal secretions, impaired MCC and a predisposition to bacterial infection. Figure 2 depicts the pharmacological modulation of the ion (and liquid) transport due to the action of amiloride and UTP across the airway epithelium in CF patients in comparison with healthy subjects $[3,4]$.

\section{Amiloride}

Data regarding the effect of amiloride on MCC are conflicting. Some authors were unable to demonstrate an influence of the single [5] or long-term (during 6 months) [6] inhalation of amiloride on pulmonary MCC in $\mathrm{CF}$ patients, while others showed a stimulatory effect after acute [7, 8] and long-term (during 3 weeks) [7] exposure in these patients. MidDlETON et al. [9] found that nasal MCC was improved after acute inhalation of amiloride in $\mathrm{CF}$ patients as well as in normal subjects. Differences in

b)

Airway lumen

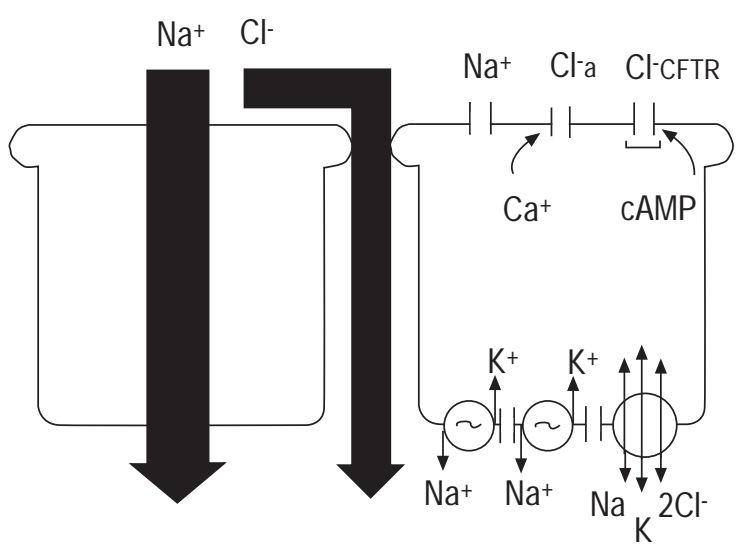

Submucosa

Fig. 1. - Net ion flow across the airway epithelium in: a) normal; and b) cystic fibrosis (CF) subjects under basal conditions, and the key cellular transport elements. The increased active $\mathrm{Na}^{+}$absorption across the epithelia of $\mathrm{CF}$ subjects is associated with increased $\mathrm{Na}^{+}-\mathrm{K}^{+}-$adenosinetriphosphatasae sites on the basolateral membrane. The cyclic adenosine monophosphate (cAMP)-mediated lumenal membrane conductance associated with the CF transmembrane conductance regulator (CFTR) is dysfunctional in CF (capped off), but an alternative $\mathrm{Cl}^{-}$conductance $\left(\mathrm{Cl}^{-} \mathrm{a}\right)$ that is $\mathrm{Ca}^{2+}$-activated is present in both normal and CF epithelia. (From [3], with permission.) 
a)

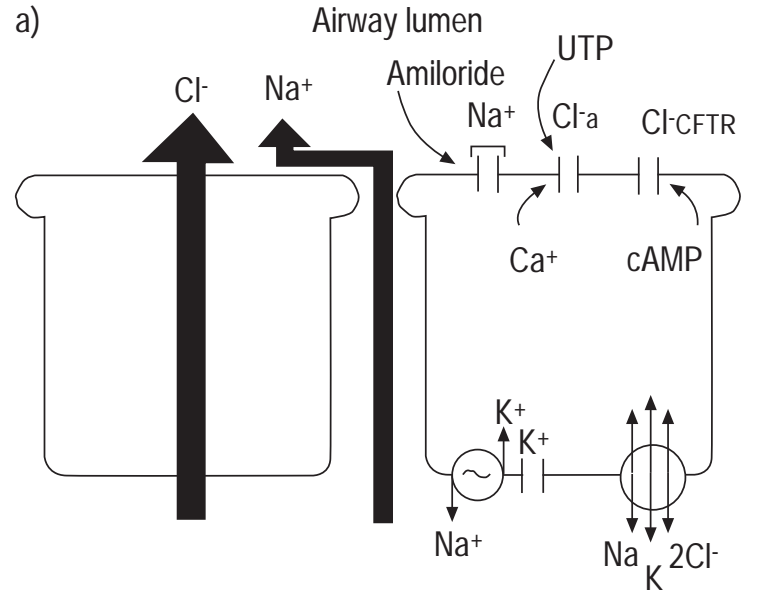

Submucosa

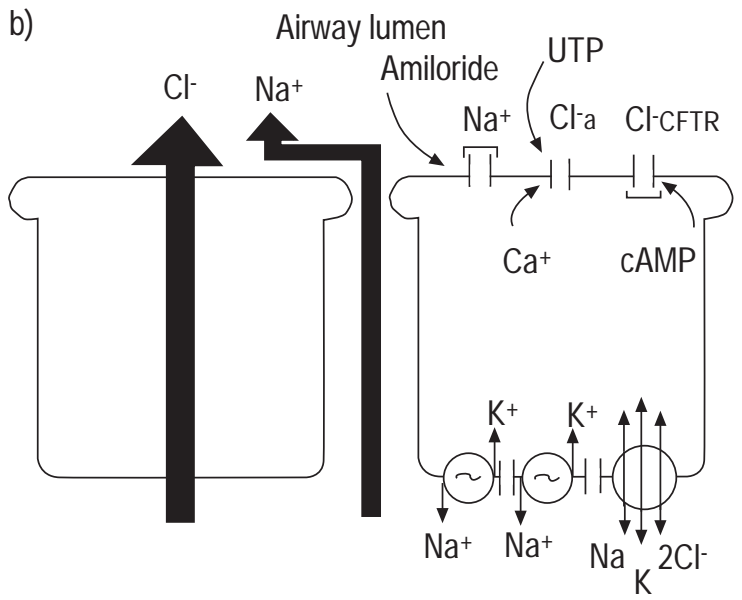

Submucosa

Fig. 2. - Net ion flow across the airway epithelium in normal and cystic fibrosis (CF) subjects after lumenal amiloride and uridine triphosphate (UTP) administration. Amiloride inhibits $\mathrm{Na}^{+}$absorption and UTP induces $\mathrm{Cl}^{-}$secretion by activating non-cystic fibrosis transmembrane regulator (CFTR) $\mathrm{Cl}^{-}$ channels. (From [3], with permission). $\mathrm{Cl}^{-} \mathrm{a}$ : alternative $\mathrm{Cl}$ - conductance; cAMP: cyclic adenosine monophosphate.

the administered dose of amiloride may contribute to these contrasting findings.

It may be important to initiate amiloride treatment as early in life as possible. App et al. [7], for example, noted that no enhancement of clearance was seen in CF patients who already had a history of pneumonia. The data of RoBINSON et al. [5] also indicated that the effectiveness of amiloride is probably higher when the drug is administered before significant lung damage has occurred.

The action of amiloride on MCC is suggested to be short-lived. KöHLER et al. [8] have shown that the effect of an inhaled dose of $70 \mu \mathrm{g}$ amiloride on MCC reached its maximum within the first $30 \mathrm{~min}$ and lasted $\sim 60-80 \mathrm{~min}$ in CF patients. App et al. [7] have demonstrated that amiloride lost its beneficial effect on MCC after $40 \mathrm{~min}$ and is only significantly enhanced during the first $10 \mathrm{~min}$ after administration. Consequently, the question arises as to whether it is useful to add amiloride to the drug management of CF patients in order to improve MCC.

There are data available discussing not only the effect of amiloride on MCC, but also its effect on the different components of this mechanism. CuRTIS and Misch [10] studied the influence of amiloride $\left(10^{-5} \mathrm{M}\right)$ on the CBF as measured on the surface of an isolated frog palatal epithelium. No change in CBF was observed after the application of amiloride. Di Benedetto et al. [11, 12] showed that amiloride at a concentration of $10^{-4}$ and $10^{-3}$ $\mathrm{M}$ has a small, but statistically significant effect on $\mathrm{CBF}$ after $1 \mathrm{~min}$ of exposure to the drug, but not after 15 or 30 min as recorded in vitro in 10 samples of healthy human bronchial epithelium. Lower concentrations of amiloride did not influence the CBF. Although amiloride has augmented the ciliary activity, this increase in $\mathrm{CBF}$ probably does not play a major role in MCC due to the weakness and short duration of its action. The influence of amiloride on other factors involved in MCC must be determined.

CuRTIS and Misch [10] observed that amiloride stimulated 2.5-3 times more cells to secrete mucus on the frog palate. This was correlated with an increase of $28 \%$ in viscoelasticity of the mucus transport layer measured in situ (approximated by determining the breaking strength of mucus using a surface tension balance). In contrast to these findings, App et al. [7] showed that $\mathrm{CF}$ sputum filance values, used as an index of viscoelasticity, decreased significantly after the inhalation of amiloride $\left(10^{-3} \mathrm{M}\right)$ compared to placebo (normal saline) in CF patients. GRAHAM et al. [6] could not find a statistically significant difference in the rheological properties of CF sputum between a 6-month amiloride (3.8 $\mathrm{mM}$ ) or placebo treatment while the patients continued to use their current medication.

In addition to MCC, CC may also be altered by amiloride treatment. The single as well as the long-term inhalation of amiloride was shown to increase CC significantly in CF patients [7, 8]. Similarly, KNowles et al. [13] predicted that long-term treatment with amiloride improves $\mathrm{CC}$ in $\mathrm{CF}$ due to mucus rheological changes.

Since both MCC and $\mathrm{CC}$ may be improved after treatment with amiloride, the question arises as to whether treatment with this agent is of clinical importance. The data of KNOwLES et al. [13] showed that the decline in pulmonary function associated with CF was slowed down after a 25 -week treatment period with amiloride. Statistical significance was only reached for the forced vital capacity (FVC) and not for the forced expiratory volume in one second (FEV1). Conversely, GraHAM et al. [6] were unable to confirm these results. No changes in FVC, FEV1 and the frequency of infective exacerbations were noted when amiloride was added to the existing treatment.

\section{Uridine 5'-triphosphate}

UTP and adenosine $5^{\prime}$-triphosphate (ATP) regulate specific activities of airway epithelial cells that are components of the mucociliary transport system. Augmented goblet cell degranulation [14], increased tracheal gland secretion [15], stimulated CBF [16] and elevated liquid secretion $[17,18]$ are noted.

OLIVIER et al. [19] showed that UTP $\left(10^{-2} \mathrm{M}\right)$ alone or in combination with amiloride $\left(1.3 \times 10^{-3} \mathrm{M}\right)$ caused a 2.5-fold increase in MCC in normal human adults. 
Similarly, aerosolized UTP $\left(10^{-2} \mathrm{M}\right)$ in combination with amiloride $\left(1.5 \times 10^{-3} \mathrm{M}\right)$ significantly improved the MCC from the peripheral airways in adult $\mathrm{CF}$ patients to near normal values during the first $40 \mathrm{~min}$ of the measurement, after which the response decreased [20]. UTP or amiloride alone, however, was not shown to have a statistically significant influence on MCC.

In conclusion, data regarding the influence of amiloride as well as UTP on MCC in humans are not unequivocal. It is important to find out why in some studies amiloride or UTP are effective in enhancing MCC, whereas in other studies they do not alter MCC. Differences in study design such as the administered dose of amiloride as well as the mean age of the patients examined are mentioned by RoBinson et al. [5] to explain the discrepancies between their results and those of ApP et al. [7]. Additionally, data obtained in healthy subjects are difficult to compare with data obtained in CF patients in whom MCC is impaired. In addition to $\mathrm{MCC}, \mathrm{CC}$ is reported to be improved after amiloride treatment in $\mathrm{CF}$ patients. The clinical significance of amiloride treatment for patients is still a matter of discussion.

\section{Cholinergics}

Despite their beneficial effect on lung MCC, cholinergic agonists are not used therapeutically since they play a mediating role in the constriction of bronchial smooth muscle [21-23]. Cholinergics are used clinically to test for bronchial hyperreactivity.

Administration of 5.0-7.5 mg bethanecol hydrochloride subcutaneously to eight healthy nonsmoking subjects was shown to result in a statistically significant enhancement of MCC from the proximal airways [24].

An increase in mucus secretion after the administration of cholinergic agonists was observed by different investigators. LOGUN et al. [25] as well as BOAT and KLEINERMAN [26] reported that different doses of metacholine stimulated the discharge of respiratory glycoproteins in human bronchial explant cultures. SHelhamer et al. [27] also found an augmented mucus release due to the addition of metacholine $(100 \mu \mathrm{M})$ in human bronchial airways obtained after surgical resection. Rogers et al. [28] noted that metacholine $(10 \mu \mathrm{M})$ caused a significant increase, in vitro, in the rate of secretion in bronchi with carcinoma but not in CF airways.

Additionally, an increase in CBF has been shown by IraVANI and Melville [29]. Acetylcholine and pilocarpine caused cilioexcitation in rat bronchial preparations in vitro.

\section{Anticholinergics}

Anticholinergic drugs are known to be effective bronchodilators [30]. However, reports have been published illustrating the less favourable effect of some anticholinergics on MCC. The influence of tertiary ammonium compounds, such as atropine and hyoscine, on lung MCC were demonstrated to be different from those of quaternary ammonium compounds, such as ipratropium bromide and oxitropium bromide.
Tertiary ammonium compounds are reported to impair the mucociliary transport system. YeATES et al. [31] showed that the tracheal mucus velocity (TMV) in four healthy subjects decreased for at least $3 \mathrm{~h}$ after the intravenous injection of $1 \mathrm{mg}$ of atropine in one subject and $0.6 \mathrm{mg}$ in the other three. In agreement with their findings are those of Foster et al. [32] who found that an oral dose of atropine $(0.8 \mathrm{mg})$ delayed $\mathrm{MCC}$ in a group of normal subjects. Atropine administered prior to an adrenergic aerosol, however, did not alter the stimulatory effect of the adrenergic agent on MCC. PAVIA and THOMson [33] showed that the oral administration of hyoscine $(8 \mu \mathrm{g} \cdot \mathrm{kg}$ body weight ${ }^{-1}$ ) caused a significant retardation in human bronchial MCC.

A decrease in $\mathrm{CBF}$ caused by these agents may be responsible for the observed decrease in MCC. Indeed, atropine has been shown to cause a dose-related reduction in $\mathrm{CBF}$, ranging from $8 \%$ at $10^{-6} \mathrm{~g} \cdot \mathrm{mL}^{-1}$ to $31 \%$ at $10^{-3}$ $\mathrm{g} \cdot \mathrm{mL}^{-1}$, in the isolated airway preparation of the rat, cat, hamster and monkey [34].

Tertiary ammonium compounds are, however, not only claimed to influence the CBF, but also the secretion of mucus in healthy subjects as well as in different patient groups. The augmented secretion of mucus induced by metacholine is shown to be blocked by atropine in human airway epithelium in vitro $[26,27]$. Atropine alone, however, had no effect on the release of mucus [27]. LopezVIDRIERO et al. [35] found that atropine had an inhibitory effect on bronchial gland secretion in three patients (with a diagnosis of chronic bronchitis, intrinsic asthma or bronchiectasis in combination with bronchorrhoea). The single administration of atropine (either by inhalation or intramuscular injection) is reported not to alter sputum viscosity in patients with chronic bronchitis, asthma or bronchiectasis $[35,36]$.

The influence of quaternary ammonium compounds on MCC is different from that of tertiary ammonium compounds. The single administration of low doses of ipratropium bromide (dosage ranging 16-80 $\mu \mathrm{g}$ ) is reported not to influence MCC in normal subjects [37] as well as in patients with chronic obstructive bronchitis [38, 39] or bronchial asthma [40]. Moreover, RufFin et al. [41] noted a significant increase in MCC after the inhalation of high dose ipratropium bromide $(200 \mu \mathrm{g})$ in six healthy subjects compared to the effect of the propellant alone (placebo). The same trend was noted in six bronchitic patients, although statistical significance was not reached. The inhalation for several days of low dose ipratropium bromide $(40 \mu \mathrm{g}, q . i . d$.), however, did not alter the MCC in patients with chronic obstructive bronchitis [38, 39] nor did the inhalation of high dose ipratropium bromide for 4 weeks (200 $\mu \mathrm{g}$, three times per day) in patients with chronic obstructive pulmonary disease (COPD) or asthma [42].

Concerning the influence of quaternary ammonium compounds on the CBF, IRAVANi and Melville [34] showed that ipratropium bromide had a mild depressant effect on the $\mathrm{CBF}$ in the isolated airway preparation of the rat, cat, hamster and monkey. The reduction in CBF was not doserelated and averaged $8 \%$ over a dose range $10^{-7}-10^{-3}$ $\mathrm{g} \cdot \mathrm{mL}^{-1}$.

Mostly, quaternary ammonium compounds did not influence mucus production nor the rheological properties. The inhalation of ipratropium bromide (total dose 160-600 
$\mu \mathrm{g} \cdot$ day $^{-1}$ ) during a period ranging 3 days to 4 weeks did not have any effect on the sputum viscoelastic properties in patients with chronic bronchitis [43, 44], asthma [42, 44] or COPD [42]. Additionally, no effect on the sputum volume was observed $[42,44]$. In contrast, TAMAOKI et al. [45] noted that sputum production decreased from $61 \pm 4$ to $42 \pm 3 \mathrm{~g} \cdot \mathrm{day}^{-1}$ and the sputum elastic modulus increased from $68 \pm 12$ to $97 \pm 20$ dyne $\cdot \mathrm{cm}^{-2}$ after the inhalation of $300 \mu \mathrm{g}$ oxitropium bromide compared to placebo for 8 weeks in 33 patients with either chronic bronchitis or diffuse panbronchiolitis. All patients had been continuously expectorating $>30 \mathrm{~g}$ of sputum per day for at least 2 weeks before the study. Although the dynamic viscosity of the sputum tended to increase, no statistical significance was reached.

Although quaternary ammonium compounds are reported not to alter or even to increase MCC, care must be taken when administering these agents to patients since the inhalation of ipratropium bromide $(40 \mu \mathrm{g})$ has been shown to diminish the effectiveness of cough in clearing the radiolabeled particles from the airways in patients with stable moderate-to-severe airway obstruction [46]. The authors thought that this could be due to changes in the airflow dynamics induced by bronchodilatation or altered rheology or depth of airway secretions.

In conclusion, tertiary ammonium compounds are claimed to decrease MCC. A reduction in CBF as well as a decreased rate of mucus secretion might be responsible for this observed retardation of the mucociliary transport system. No influence of these agents on sputum viscosity has been demonstrated. In contrast, quaternary ammonium compounds are reported not to alter MCC or even to increase MCC. Surprisingly, a reduction in CBF after the administration of these agents in animals was observed. The production of sputum is suggested to be unaltered or decreased after drug administration. The rheological properties are mostly demonstrated not to be influenced by the inhalation of quaternary ammonium compounds. $\mathrm{CC}$, however, is suggested to be impaired after treatment with ipratropium bromide.

\section{Adrenergic agonists}

Adrenergic agents are bronchodilators. In addition to their relaxing effect on the bronchial smooth muscle, adrenergic agonists are also reported to have an influence on MCC. All adrenergic agonists mentioned in this article are $\beta$-adrenergic agonists except for epinephrine and associated agents which are $\alpha$-adrenergic agonists.

In normal subjects, the single inhalation of isoproterenol [32, 47], epinephrine [32], salbutamol [48], terbutaline $[49,50]$, fenoterol $[31]$ as well as isoetharine hydrochloride [47] have been shown to augment MCC significantly. It is noteworthy that the increase in MCC evoked by the inhalation of an adrenergic agent (terbutaline $1 \mathrm{mg}$ ) in healthy subjects was larger than that found in patients with asthma, bronchiectasis or CF studied by the same investigators [49]. Other routes of drug administration besides inhalation are also reported to be efficient. Thus, Foster et al. [32] noted a significant increase in MCC after the administration of a sublingual dose of isoprenaline $(10 \mathrm{mg})$ in normal subjects. Similarly, KonIETZKo et al. [51] found MCC to be enhanced after the oral administration of terbutaline $(5 \mathrm{mg})$ in healthy subjects. CAMner et al. [52] showed that the subcutaneous administration of terbutaline sulphate $(0.25 \mathrm{mg})$ produced a sharp increase in MCC in normal subjects.

Not all studies, however, found a significant improvement in the functioning of the mucociliary apparatus after the administration of adrenergic agonists. Oral administration of orciprenaline $(20 \mathrm{mg})$ to healthy nonsmoking males led to a significant increase in TMV but not in bronchial clearance [53]. SPEKTOR et al. [54] were unable to demonstrate any consistent effect of orally administered alupent $(20 \mathrm{mg})$ on TMV and MCC in healthy nonsmoking adults. Similarly, the subcutaneous injection of terbutaline $(0.25 \mathrm{mg})$ did not augment the TMV significantly in healthy subjects [55], while three puffs $(30 \mu \mathrm{g})$ of procaterol neither accelerated mucus transport in the large airways, determined by cinescintigraphy, nor facilitated lung MCC, as measured by the changes in the slope of time/activity curves, in normal subjects or patients with various lung diseases [56].

Most literature regarding the influence of adrenergic agonists on the mucociliary mechanism in disease, have focused on chronic bronchitis. The inhalation of fenoterol $(400 \mu \mathrm{g})$ [57] or salbutamol $(500 \mu \mathrm{g})$ [48] as well as the oral administration of terbutaline $(5 \mathrm{mg})$ [51] is reported to enhance MCC in patients with chronic bronchitis. However, terbutaline ( $0.25 \mathrm{mg}$ subcutaneously) administered to 10 patients with chronic bronchitis was shown to produce a marked increase in MCC in four patients, a smaller increase in one and had no effect in the others [58]. Three of the four patients who responded well had a history of rather mild chronic bronchitis and had little or no ventilatory impairment. Additionally, the ventilatory impairment of the fourth patient may have been caused by restrictive changes. Indeed, the authors assumed that the response to $\beta$-adrenergic stimulation is better in the relatively early stages of chronic bronchitis since the mucociliary transport system is less severely damaged at that point. SACKNER et al. [59] agreed that the extent of impairment of the mucociliary transport mechanism may limit the effectiveness of adrenergic agonists in promoting an increase in mucus transport, since the inhalation of fenoterol $(400 \mu \mathrm{g})$ did not increase the TMV in patients with chronic bronchitis who had markedly slowed or absent mucus transport.

However, it is important to study not only the acute but also the effect of the administration for several days of an adrenergic agonist on MCC. Thus, the oral administration of tulobuterol ( $4 \mathrm{mg} \cdot \mathrm{day}^{-1}$ for 1 week) [60], fenoterol (7.5 $\mathrm{mg} \cdot \mathrm{day}^{-1}$ for 1 week) [60] or clenbuterol $\left(0.06 \mathrm{mg} \cdot \mathrm{day}^{-1}\right.$ for 4 days) [61] to patients with COPD or asthma is shown to result in a significantly enhanced MCC. In contrast, the four times daily inhalation of terbutaline (500 $\mu \mathrm{g})$ for 1 week in 10 patients with chronic obstructive bronchitis did not change the rate of MCC [39]. Similarly, no significant effect on MCC with the oral administration of terbutaline $(2.5 \mathrm{mg}$ tablets three times a day for 1 week) to 20 patients with chronic bronchitis was demonstrated, as well as the viscoelastic properties of the sputum and the in vitro transport rate on the frog palate [62].

Finally, since smoking is a significant factor contributing to the development of chronic bronchitis, the findings of Foster et al. [63] are worth noting at this point. They found that young, asymptomatic smokers with only a 
small abnormality in FEV1 had MCC values comparable to age-matched healthy subjects, and responded to $\beta_{2}$ adrenergic aerosol with enhanced lung clearance and transport for mucus as did healthy subjects. The same authors later reported [64] that the inhalation of isoetharine hydrochloride $\left(5 \times 10^{-3} \mathrm{M}\right.$ in $\left.2.25 \mathrm{~mL} 0.9 \% \mathrm{NaCl}\right)$ augmented MCC in a group of smokers with normal pulmonary function to the baseline control rates of the nonsmokers. MORTENSEN et al. [65] noted that the inhalation of five puffs of terbutaline significantly increased MCC in healthy smokers.

The influence of adrenergic agonists on MCC is studied less in asthmatics than in chronic bronchitics. The inhalation of fenoterol $(0.6 \mathrm{mg})$ caused a significant increase in MCC in patients with bronchial asthma [66] as did the subcutaneous administration of terbutaline $(0.25 \mathrm{mg})$ [67], but to a lesser extent than in healthy subjects [52]. This weak effect of terbutaline on MCC in asthmatics, might be explained by a defect in the mucociliary apparatus caused by the disease itself or by increased tolerance and/ or by carry-over effects of earlier treatments with $\beta$ adrenergic medication or other drugs [67]. BATEMAN et al. [68], however, mentioned that the inhalation of terbutaline sulphate $(1 \mathrm{mg})$ did not enhance $\mathrm{MCC}$ in patients with mild stable asthma, while a 2 -week treatment period with salbutamol ( $8 \mathrm{mg}$ twice daily in tablet form) had no effect on the reduced rate of clearance associated with sleep in stable asthma [69].

Contrasting findings are reported regarding the effect of adrenergic agonists on MCC in CF patients. The subcutaneous injection of terbutaline $(0.25 \mathrm{mg})$ was reported to augment the TMV significantly in adult CF patients in whom the TMV was markedly depressed in comparison with normal subjects as measured before drug administration [55]. Conversely, inhalation of terbutaline (1 mg) did not improve MCC in young patients with $\mathrm{CF}$ [70]. Surprisingly, a trend towards an increased CC was observed in these patients after the inhalation of terbutaline compared to placebo.

The influence of adrenergic agonists on $\mathrm{MCC}$ in patients with bronchiectasis is promising, since the inhalation of terbutaline $(1 \mathrm{mg})$ significantly improved whole lung tracheobronchial clearance in such patients [71].

MCC is a complex mechanism, wherein many variables are present, all of which may modify the final outcome. Devalia et al. [72] studied the effect of salbutamol $\left(10^{-8}\right.$ $\left.10^{-3} \mathrm{M}\right)$ and salmeterol $\left(10^{-8}-10^{-4} \mathrm{M}\right)$ on the CBF of cultured human bronchial epithelium, derived from surgical explants. Salmeterol is an inhaled $\beta_{2}$-adrenoceptor agonist which is more potent and has a longer duration of action than salbutamol. Both agents increased the CBF significantly during the study, although the effect of salmeterol was much more potent, faster and longer acting than salbutamol.

Studies investigating the influence of adrenergic agents on the secretion rate of mucus in human airways have found opposing data. In the bronchi of human lungs surgically removed from patients with bronchial carcinoma, phenilephrine, dobutamine as well as salbutamol increased the rate of secretion of radiolabelled glycoproteins, used as an index of the rate of mucus secretion [73]. SHelHAmer et al. [27] have shown that $\alpha$-adrenergic but not $\beta$-adrenergic agents increased mucus secretion in the human bronchial tree in vitro. BOAT and KLEINERMAN [26] observed that neither $0.5-25 \mu \mathrm{g} \cdot \mathrm{mL}^{-1}$ isoproterenol nor $10 \mu \mathrm{g} \cdot \mathrm{mL}^{-1}$ norepinephrine bitartrate influenced the discharge rate of macromolecule release in human tracheal epithelium obtained from patients dying without significant pulmonary disease. Rogers et al. [28] could not show any significant effect of terbutaline $(10 \mu \mathrm{M})$ on the rate of secretion in bronchial segments of $\mathrm{CF}$ patients. The reason for this discrepancy in the results must be studied further.

In conclusion, MCC seems either to remain unchanged or to increase after the administration of adrenergic agonists in health as well as in different lung diseases. Different routes of drug administration are effective. CC is suggested to be improved after the administration of adrenergics in $\mathrm{CF}$ patients. Why adrenergic agonists increase MCC in some cases whereas in others they do not alter MCC, requires further investigation. The extent of the impairment of the mucociliary transport system, for example, is suggested to limit the effectiveness of adrenergic stimulation on MCC. Increased tolerance and/or carry-over effects of earlier treatments with adrenergics is also claimed to reduce the stimulatory effect of these agents on MCC.

\section{Adrenergic antagonists}

$\beta$-Adrenergic antagonists are frequently prescribed for patients with cardiac disease. Very little research, however, has been undertaken regarding the effect of these agents on MCC. Thus, both selective (atenolol tablets $100 \mathrm{mg}$ ) and nonselective (propranolol tablets $160 \mathrm{mg}$ ) $\beta$-adrenoceptor blockade did not alter MCC in normal subjects [74]. Thymoxamine, an $\alpha$-adrenoceptor antagonist, but not propranolol, a $\beta$-adrenoceptor antagonist, could block the increase in glycoprotein secretion in human bronchi in vitro caused by phenylephrine, an $\alpha$-adrenoceptor agonist [73]. Additionally, propranolol but not thymoxamine blocked the stimulative effect on glycoprotein release produced by dobutamine, a $\beta_{1}$-adrenoceptor agonist. The increased rate of secretion caused by salbutamol, a $\beta_{2-}$ adrenoceptor agonist, was equally blocked by propranolol. Further studies are needed to examine the influence of adrenergic agonists on MCC and its component functions in humans, particularly in patients with lung disease.

\section{Methylxanthines}

Methylxanthines are indicated for the treatment of bronchoconstriction in some patients. Additionally, these agents are demonstrated to have a stimulative effect on lung MCC. Cotromanes et al. [75] observed a trend towards an increase in TMV after the ingestion of theophylline ( $4 \mathrm{mg} \cdot \mathrm{kg}$ body weight ${ }^{-1}$, twice daily) for 3 days compared to placebo treatment in healthy subjects. Despite the increased peripheral aerosol deposition after theophylline treatment, MCC did not differ between theophylline or placebo-treated subjects, suggesting that theophylline increased the rate of MCC in the intrapulmonary airways. SutTon et al. [76] noted a significant increase in lung MCC after oral administration of aminophylline (450 mg twice daily) for 7 days in patients with obstructive lung disease (including patients with asthma, chronic bronchitis and bronchiectasis) when compared to placebo treatment. Treatment with bamiphylline $(600 \mathrm{mg}$ 
twice daily) for 15 days significantly improved tracheobronchial mucus clearance in smokers with simple chronic bronchitis when compared to placebo treatment [77]. Two weeks of treatment with theophylline $(350 \mathrm{mg}$ twice daily) was, however, shown not to exert any effect on the reduced rate of clearance associated with sleep in asthmatics [69].

Although the results of the influence of methylxanthines on lung MCC are promising, the data have to be interpreted with caution. Pearson et al. [78] showed that in subjects with irreversible airflow limitation due to emphysema, MCC was not significantly different after intravenous administration of aminophylline (loading dose of $6 \mathrm{mg} \cdot \mathrm{kg}^{-1} \cdot \mathrm{min}^{-1}$ over $45 \mathrm{~min}$ followed by a maintenance dose of $0.9 \mathrm{mg} \cdot \mathrm{kg}^{-1} \cdot \mathrm{min}^{-1}$ for $4 \mathrm{~h}$ during the study) compared to a control regimen where nothing was given. Marked variations, however, were noted in clearance between study days and between individuals. These differences were compatible with the known effects of airways obstruction and breathing patterns on the sites of particle deposition within the bronchial tree. The latter factors appeared to have a greater influence on the observed MCC than did aminophylline.

The mechanism responsible for the observed improvement in MCC still remains a matter of debate. Thus, aminophylline has been shown to stimulate in vitro the transepithelial secretion of fluid into the canine airway lumen [79] and to exert a cilioexcitatory effect in isolated preparations of the rat bronchial tree [29]. Addition of theophylline caused an increased discharge in normal and hypertrophied human submucosal glands in vitro [80].

In conclusion, methylxanthines appear to enhance MCC in healthy subjects. In patients with obstructive lung disease, a significant increase in MCC is present after a prolonged administration of these agents. Administration of methylxanthines might increase the secretion of mucus, augment the $\mathrm{CBF}$ as well as stimulate the secretion of fluid into the airway lumen, all factors involved in the final outcome of MCC. To the best of the authors' knowledge, no studies have investigated the influence of methylxanthines on $\mathrm{CC}$ in humans.

\section{Corticosteroids}

Corticosteroids are used in the management of acute exacerbations in patients with chronic obstructive lung disease and asthma. Corticosteroids, however, are also claimed to influence MCC. Oral corticosteroid treatment (2 weeks of $15 \mathrm{mg}$ prednisolone day $^{-1}$, plus 2 weeks of $30 \mathrm{mg}$ prednisolone. day $^{-1}$ ) given to stable asthmatics led to a significant improvement in clearance from the peripheral and the intermediate regions of the lungs [81]. Clearance from the inner region of the lungs was only significantly increased in the six patients who coughed relatively infrequently prior to treatment. Conversely, no significant difference in $\mathrm{MCC}$ after the inhalation of beclomethasone dipropionate $(250 \mu \mathrm{g})$ or placebo was observed in patients with COPD [82]. Since the incidence of chest infections is claimed to be increased in patients taking aerosol steroids compared to those receiving oral preparations [83], mechanisms other than an impaired mucociliary transport must be responsible for the increased incidence of respiratory infections observed after the inhalation of steroids.
Regarding the influence of corticosteroids on different variables associated with MCC, IRAVANI and MELVILLE [29] showed that corticosteroids (both pilocarpine and prednisolone) were able to increase the CBF significantly in isolated bronchial preparations in rats. Additionally, dexamethasone and methylprednisolone produced a doserelated suppression of the spontaneous release of mucus glycoproteins studied in vitro in human airways [84]. Corticosteroid-treated airways also had a reduced airway secretion after stimulation by histamine or 5-hydroxyeicosatetraenoic acid (5-HETE). This was explained by a lowered baseline secretion rate, rather than by a specific inhibition of either secretagogue. Different mechanisms by which glucocorticosteroids are able to inhibit the secretion of mucus in asthmatic airways are described by LundGRen et al. [85]. Agnew et al. [86] noted that five asthmatic patients who were initially sputum producers ceased to produce sputum after 4 weeks of oral corticosteroid treatment.

In conclusion, while one study demonstrated that MCC was increased in asthmatics after treatment with corticosteroids, an unchanged MCC in patients with COPD was reported in another study. An increase in CBF as well as a reduction in the rate of mucus secretion are suggested to be involved in the enhancement of the mucociliary clearance mechanism. Further studies are needed to examine the effect of corticosteroids on mucus clearance as well as its clinical significance.

\section{Recombinant human deoxyribonuclease}

In pathological states, deoxyribonucleic acid (DNA) may be found in mucus [87], particularly in CF patients $[88,89]$. An increase in CF mucus DNA content is associated with an increase in mucus viscosity and mucus elastic modulus [89]. Recombinant human deoxyribonuclease (rhDNase) has been shown to cause a reduction in sputum DNA size [90].

Literature concerning the in vitro effect of rhDNase on the rheological and surface properties of $\mathrm{CF}$ respiratory sputum are mostly unanimous. rhDNase appears to reduce CF sputum viscoelasticity $[89,91-96]$ and improve its surface properties as demonstrated by a decrease in the contact angle $[89,92,96]$. The adhesiveness of CF mucus was shown to decrease after the in vitro incubation with rhDNase [93]. The dose of rhDNase used in these studies ranged $0.2 \mu \mathrm{g} \cdot \mathrm{mL}^{-1}-1 \mathrm{mg} \cdot \mathrm{mL}^{-1}$. One study [97] reported that the $\mathrm{CF}$ sputum viscoelasticity was reduced after 10 days of in vivo rhDNase $(2.5 \mathrm{mg})$ administration to CF patients. DASGUPTA and KING [98] found a decrease in CF sputum spinnability, but not in viscoelasticity, after in vitro incubation of the sputum with rhDNase $\left(25 \mu \mathrm{g} \cdot \mathrm{mL}^{-1}\right)$.

The addition of rhDNase $\left(20 \mu \mathrm{g} \cdot \mathrm{mL}^{-1}\right)$ to $\mathrm{CF}$ mucus resulted in a significant augmentation of the $\mathrm{CBF}$ as measured on the frog palate [96].

Since it was shown that rhDNase alters the rheological properties of $\mathrm{CF}$ respiratory mucus and was even suggested to have an effect on $\mathrm{CBF}$, it may be suspected that rhDNase influences MCC. Indeed, rhDNase at a concentration of $1 \mathrm{mg} \cdot \mathrm{mL}^{-1}$ caused an increase in the transportability of CF secretions on the frog palate [93]. In contrast, ZAHM et al. [89] did not observe a significant dosedependent effect of rhDNase $\left(0.2,2\right.$ or $20 \mu \mathrm{g} \cdot \mathrm{mL}^{-1}$ of 
mucus) on the mucociliary transport rate of $\mathrm{CF}$ respiratory mucus as measured on the frog palate. In fact, the mucociliary transport rate did increase but only in the mucus samples with a low initial mucociliary transport rate, while it decreased in the mucus samples with high initial transport rate. WILLS et al. [99] have investigated the effect of rhDNase on the in vitro sputum transportability in patients with bronchiectasis not caused by $\mathrm{CF}$ using the mucus-depleted bovine trachea. The patients received rhDNase $2.5 \mathrm{mg}$ twice daily, rhDNase $2.5 \mathrm{mg}$ once daily or placebo by inhalation for 14 days. No significant change in sputum transportability was observed. When the drug was incubated with bronchiectatic sputum in vitro to a final concentration of $50 \mu \mathrm{g} \cdot \mathrm{g}^{-1}$, a fall in transportability was noticed.

Combined treatment of rhDNase with either neutral $(0.9 \% \mathrm{NaCl})$ or hypertonic saline $(3 \% \mathrm{NaCl})$ revealed that the spinnability of CF sputum was significantly reduced [100]. No clear evidence for synergy of mucolytic action between rhDNase and hypertonic saline was present. Additionally, the combined treatment of rhDNase with hypertonic saline but not with neutral saline significantly decreased the viscoelasticity of the sputum to a similar degree as incubation with hypertonic saline alone. This suggests that the observed effect was mainly due to hyper-tonic saline and that rhDNase had a smaller additional effect on viscoelasticity in these samples.

Indirect data suggest that the administration of rhDNase might improve CC in CF patients. The $\mathrm{CC}$ index, calculated from the viscoelastic properties of the mucus, was significantly increased in CF patients after treatment with rhDNase (2.5 mg twice daily) for 10 days compared to placebo [101]. Similarly, the transport by cough as measured in the cough machine developed by KING et al. [102], was improved in a dose-dependent manner after the addition of $0.2,2$ or $20 \mu \mathrm{g} \cdot \mathrm{mL}^{-1}$ of $\mathrm{CF}$ respiratory mucus [89].

Treatment with rhDNase is shown to improve pulmonary function in a dose-dependent manner and to decrease the incidence of respiratory tract infective exacerbations requiring parenteral antibiotic therapy [103]. It also reduces the rate of hospitalizations as well as the number of days missed from school or work, decreases the frequency of CF related symptoms and improves the patients' wellbeing, as reviewed by Hodson [104] and SHAK [105].

In conclusion, in most studies, rhDNase was shown to decrease the rheological as well as the surface properties of $\mathrm{CF}$ respiratory mucus. An increase in the CBF due to the addition of rhDNase to $\mathrm{CF}$ sputum is also suggested to occur. The effect of rhDNase on the mucociliary transport rate as measured on the frog palate is probably dependent on different factors, such as the initial mucociliary transport rate and the concentration of rhDNase. It was, however, shown that rhDNase is able to increase the mucociliary transport rate of $\mathrm{CF}$ sputum. No significant changes in the mucociliary transport rate of sputum from patients having bronchiectasis not caused by CF were noted as measured on the mucus-depleted bovine trachea. The CC is suggested to be improved after treatment with rhDNase in $\mathrm{CF}$ patients. Further studies are required to find out when and why rhDNase is effective in enhancing mucus transport in vivo. This is even more important since treatment with this agent is shown to have clinically beneficial repercussions in CF.

\section{Sodium cromoglycate}

Sodium cromoglycate is prescribed to asthmatic patients for prophylactic purposes against asthmatic attacks [106]. Bronchial provocation induced a decrease in TMV $\leq 72 \%$ of baseline after challenge with ragweed that resulted in a $\geq 35 \%$ fall of the specific airway conductance in asymptomatic asthmatics with ragweed hypersensitivity [107]. Although the respiratory mechanics had returned to baseline values $1 \mathrm{~h}$ after provocation, the TMV was still further depressed to $47 \%$ of baseline values. Pre-treatment with sodium cromoglycate $(20 \mathrm{mg})$, however, resulted in a $32 \%$ increase in TMV compared to baseline with a further increase to $62 \%$ after bronchial provocation with ragweed. Conversely, healthy subjects treated with the same dose of sodium cromoglycate, showed no alteration in their baseline TMV. Since the decrease in TMV may be related to the release of chemical mediators, it is suspected that sodium cromoglycate interferes with the mediators released into the airway lumen due to antigen challenge [107]. More recently, a link between the airway chloride transport and asthma has been suggested. From this point of view, sodium cromoglycate has been shown to be involved in the function of an airway epithelial chloride channel $[108,109]$. Since water follows any net movement of ions, airway surface liquid and as a consequence MCC may be altered by sodium cromoglycate.

\section{Aspirin}

Aspirin is a widely used nonprescription antipyretic, analgesic and anti-inflammatory agent. A moderate dose of aspirin (16 mg.kg body weight $\left.{ }^{-1}\right)$ is able to cause a small but statistically significant decrease in both lung MCC and tracheal mucociliary transport rate in healthy subjects [110]. To the best of the authors' knowledge, no other studies have investigated the effect of aspirin on either $\mathrm{MCC}$ or $\mathrm{CC}$ in humans.

\section{Surfactant}

Surfactant is used in the treatment of respiratory insufficiency in premature babies, based on its ability to reduce the alveolar surface tension. BROWN and PATTISHALL [111] reviewed the potential effect of surfactant on several factors other than reducing the alveolar surface tension, and discussed the different mechanisms of surfactant action. The role of surfactant in, for instance, mucus properties, ciliary activity and anti-inflammatory activity suggests that the administration of surface-active substances may increase MCC.

Outzen and Svane-Knudson [112] found that nasal MCC in healthy subjects was significantly increased immediately after spraying with surface-active substances, but not $2 \mathrm{~h}$ later. The administration of exogenous surfactant in anaesthetized dogs caused a substantial enhancement in TMV in vivo and an increase in CBF as measured on the frog palate. No significant changes in the bulk viscoelastic properties of mucus were noted [113]. 


\section{Mucolytics and expectorants}

Many mucolytics and expectorants are used in the treatment of chest disorders. Since many patients with such disorders have problems with the clearance of mucus from the lungs, it is important to understand the influence of these drugs on MCC and CC.

Thus, no measurable effect of guaifenesin (glyceryl guaicolate), a known expectorant, on in vivo nasal MCC or ex vivo nasal ciliary motility was found in healthy volunteers with a previous history of sinus disease [114]. Similarly, YeATES et al. [115] observed no effect of the oral administration of glyceryl guaiacolate $(400 \mathrm{mg})$ on MCC in 19 patients with chronic bronchitis.

$N$-acetylcysteine and $S$-carboxymethylcysteine, widely used mucolytic agents, are claimed to break the disulphide bonds of the glycoproteins present in the mucus because of their free sulphydryl groups, thereby leading to a reduction in the viscosity of the mucus.

GOODMAN et al. [116] found no difference in TMV after the single administration of $2 \mathrm{~g} S$-carboxymethylcysteine in six healthy nonsmoking subjects, eight smokers with small airway disease and chronic bronchitis and eight subjects with chronic obstructive bronchitis compared to placebo. ThOMson et al. [117] demonstrated that the rate of clearance of secretions from the lungs was not changed after the administration of $4 \mathrm{~g}$ of $S$-carboxymethylcysteine per day in syrup form during 4 or 7 days in 16 patients with chronic obstructive bronchitis. Prolonged treatment with $S$-carboxymethylcysteine $(2.25$ or 3.0 $\mathrm{g} \cdot \mathrm{day}^{-1}$ ) was shown to reduce the viscosity of the sputum of chronic bronchitic patients [118].

A significant increase in MCC after the oral administration of $N$-acetylcysteine $\left(600 \mathrm{mg} \cdot\right.$ day $\left.^{-1}\right)$ for 60 days in healthy nonsmoking subjects with slow pulmonary MCC values [119] and for 10 days in patients with simple catarrhal bronchitis [120] was observed. MCC rates returned towards pre-treatment values after a 1-week washout period [119]. In contrast, in patients with chronic bronchitis, treatment with oral $\mathrm{N}$-acetylcysteine $(600 \mathrm{mg}$ daily) for 4 weeks did not significantly affect MCC and sputum viscosity compared to baseline or placebo measurements [121].

As mentioned by Puchelle et al. [122], mucolytic drugs must be administered with great care in chronic bronchitic patients, especially in patients characterized by very low viscoelastic secretions in whom sputum has a reduced transport rate on the frog palate after incubation with $\mathrm{N}$ acetylcysteine in vitro.

Is the administration of $N$-acetylcysteine or $S$-carboxymethylcysteine accompanied by a significant clinical benefit for the patient? Oral administration of 2.25 or $3.0 \mathrm{~g}$ of $S$-carboxymethylcysteine for 8 days or 3 months in patients with chronic bronchitis was shown to result in an increase in the ease of expectoration, a reduction in cough frequency and dyspnoea, an augmentation in sputum volume output as well as an improvement in ventilation [118]. Moreover, this response was found to be dose-related. Similarly, long-term treatment with oral $N$-acetylcysteine in chronic bronchitic patients compared to placebo was shown to increase the sputum volume as well as the sputum pourability (which corresponds to a reduced viscosity). Lung function values, such as the FEV1 and the peak expiratory flow rate (PEFR), improved significantly and the patients experienced less dyspnoea [123]. The agent improved the subjective assessment of ease of expectoration as well as the severity of cough. An improvement in the subjects' clinical state was noted [123, 124]. In contrast, no significant difference was found between a 16 -week treatment period with $N$-acetylcysteine ( $4 \mathrm{mg}$ twice daily by inhalation) compared to placebo on patients' feeling of well-being, sensation of dyspnoea, intensity of coughing, mucus production or expectoration, or lung function in 51 chronic bronchitics [125]. Treatment with oral acetylcysteine for 6 months, however, reduced the number of exacerbations in patients with chronic bronchitis [126]. However, when the treatment duration was only 3 months, the occurrence of episodes of infective exacerbations was similar between $N$-acetylcysteine and placebo treatment [124].

Bromhexine is suspected to liquefy the airway mucus. Thus, treatment with oral bromhexine $\left(48 \mathrm{mg} \cdot \mathrm{day}^{-1}\right)$ for 7 days increased the mucociliary transport in 12 smokers suffering from chronic bronchitis [57]. On the other hand, the oral administration of bromhexine for 1 day did not increase MCC in eight patients with mild chronic obstructive bronchitis [127]. The pattern of particle deposition, however, changed from a central deposition to a more peripheral deposition after drug administration, resulting in a longer clearance pathway.

No effect on the efficacy of coughing was noted after the intravenous administration of bromhexine (4-8 mg) compared to placebo in patients with bronchial hypersecretion [128].

Combined administration of oral bromhexine (16 mg, three times daily) and oxytetracycline (500 $\mathrm{mg}$, twice daily) to 41 clinical stable out-patients with chronic bronchitis and irreversible airway obstruction decreased phlegm stickiness and improved the overall clinical state as judged by a physician [129]. No significant changes, however, were noted in symptoms such as cough, chest tightness, ease of breathing or sputum volume, PEFR and FEV1. Compared to a control group, HARGRAVE et al. [130] noted a trend towards a decreased incidence of postoperative bronchopneumonia after bromhexine treatment $(8 \mathrm{mg}$ intramuscular postoperatively, $16 \mathrm{mg}$ three times daily orally until the fifth day) in patients with elective upper abdominal surgery receiving routine chest physiotherapy.

Ambroxol is the eighth metabolite of bromhexine and is claimed to be a surfactant stimulating agent. As a lack of surfactant might play a role in the depression of the functioning of the mucociliary apparatus [131], treatment with ambroxol might be useful in some patients.

The effect of oral administration of ambroxol (90 $\mathrm{mg} \cdot$ day $^{-1}$ ) for 4 days in 15 patients with obstructive lung disease resulted in a significant increase in regional lung clearance in the upper third of the lung only, although a trend towards improvement was also observed in the other lung regions [61]. Whole lung clearance was not significantly enhanced. An improvement in lung aerosol distribution was observed after the drug administration in patients with obstructive emphysema. The oral administration of ambroxol $\left(90 \mathrm{mg} \cdot \mathrm{day}^{-1}\right)$ for 10 days [120] as

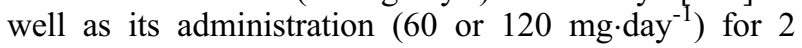
weeks [132] significantly increased the mucociliary transport in patients with simple chronic bronchitis in a dose-dependent manner [132]. Whether this effect results 
from the mucolytic properties of ambroxol or from its stimulating effect on surfactant is not known.

In contrast, ERICSSON et al. [133] showed that daily doses of $120 \mathrm{mg}$ ambroxol during 2 weeks compared to placebo treatment did not influence MCC in patients with simple chronic bronchitis, although their subjective respiratory symptoms, especially phlegm loosening, improved.

The administration of $120 \mathrm{mg}$ of ambroxol for 10 days significantly reduced the mucus viscosity in patients admitted to hospital with acute or obstructive airway disease compared to a well matched control group [134]. A daily dose of $30 \mathrm{mg}$ did not produce any changes, the response to ambroxol being dose-dependent.

WÜRTEMBERGER et al. [135] investigated whether treatment with ambroxol (30 $\mathrm{mg}$ twice daily) alone or combined with theophylline (400 mg twice daily) for 7 days caused a change in the reduced rate of clearance in patients suffering from chronic bronchitis. MCC increased significantly after the combined administration of ambroxol and theophylline, but not after ambroxol alone.

In addition to MCC, CC may also be influenced by ambroxol administration. Compared to placebo, a 2-week treatment with ambroxol (120 mg.day ${ }^{-1}$ orally) did not result in any increase in CC in subjects with simple chronic bronchitis [133] who belonged to a "responder" group in an earlier study on the subjective effects of ambroxol [136]. The authors, however, suggested that treatment with the drug might possibly have made expectoration more effective, resulting in less mucus in the experimental situation. This would tend to decrease clearance by coughing recorded experimentally, since an increased amount of secretion is necessary to make voluntary coughing effective in the clearance of particles [2]. Thus, the subjects examined in this study have reported an improvement in respiratory symptoms, principally improved expectoration, after the administration of ambroxol at a dose of $120 \mathrm{mg}$ but not after $60 \mathrm{mg}$ during a previous investigation [136]. No significant changes in lung function occurred. Germouty and JirOU-NaJOU [134] studied the effect of two different doses of orally administered ambroxol (30 and $120 \mathrm{mg}$, respectively) for 10 days in patients admitted to hospital with acute or obstructive airways disease. While the low dose of ambroxol produced a significant increase in sputum volume but no changes in difficulty of expectoration, cough, peak expiratory flow rate and sputum viscosity, the high dose led to a reduction in sputum viscosity, a more rapid improvement in expectoration and a reduction in the severity of cough. No difference in PEFR was observed.

Sodium 2-mercapto-ethane sulphonate has a terminal sulphydryl group which is claimed to break the disulphide bonds in the mucus glycoproteins as do the cysteine compounds. Thus, the inhalation of sodium 2-mercaptoethane sulphonate twice daily for 3 days enhanced the tracheobronchial clearance in patients with chronic bronchitis, although statistical significance was not reached [137]. The viscosity of the sputum, dry molecular weight and $N$-acetyl neuraminic acid/fucose ratio, however, remained unaltered. Additionally, no improvement was noted in either lung function or subjective well-being after the inhalation of this agent.

The effect of hypertonic saline on pulmonary MCC has been investigated in healthy subjects [138] and in three different patient groups, namely CF patients [5], asth- matics [138] and chronic bronchitics [137, 139]. All studies agreed that a single inhalation of hypertonic saline (although in different concentrations) increases pulmonary MCC. Moreover, a trend towards an additional improvement of MCC from the combination of amiloride and hypertonic saline has been reported [5].

KING et al. [100] demonstrated that hypertonic saline $(3 \% \mathrm{NaCl})$ significantly reduced the viscoelasticity of $\mathrm{CF}$ sputum in vitro compared to treatment with normal saline $(0.9 \% \mathrm{NaCl})$. They also noted a small decrease in the spinnability of the sputum after incubation with hypertonic saline, but significance was not reached.

The inhalation of hypertonic saline, either once or over a 3-day period, was reported to increase the mean weight of sputum in patients with COPD $[137,139]$. Attention must be paid to the fact that inhalation of aerosolized hypertonic saline is able to provoke airway narrowing in asthmatics [138].

Inhaled saline $(0.45 \% \mathrm{NaCl})$ by 10 nonsmoking normal subjects and five $\mathrm{CF}$ patients induced a significant increase in TMV in only three healthy subjects [140]. KING et al. [100] noted that the spinnability but not the viscoelasticity was significantly reduced in $\mathrm{CF}$ sputum in vitro after incubation with neutral saline $(0.9 \%)$. No increase in $\mathrm{CC}$ was found after the inhalation of neutral saline $(0.9 \%)$ in CF patients [8].

Inhalation of a water aerosol induced a slight but definite increase in MCC in normal nonsmoking subjects [32]. LIPPMANN et al. [141] reported that the administration of a tap water aerosol for $10-15 \mathrm{~min}$ in humans increased bronchial clearance rates by $\sim 25 \%$.

In conclusion, an increase in MCC was observed after treatment with hypertonic saline, saline or water aerosol. A trend towards an augmented MCC was reported after the administration of sodium 2-mercapto-ethane sulphonate. No changes in the functioning of the mucociliary transport system were found after therapy with $S$-carboxymethylcysteine or guaifenesin. $N$-acetylcysteine, bromhexine or ambroxol are shown to have either no influence or to augment MCC. It is interesting to note that ambroxol acts in a dose-dependent manner on MCC as well as on sputum viscosity.

Few studies have examined the influence of mucolytics and expectorants on $\mathrm{CC}$, which is surprising, since these agents are administered to patients in order to improve the effectiveness of coughing. Moreover, bromhexine, ambroxol and neutral saline do not alter CC.

Regarding the alteration in clinical symptoms after administering mucolytics and expectorants to patients, sodium 2mercapto-ethane sulphonate did not improve the patients' subjective well-being. Alternatively, there are studies reporting the clinical beneficial effect of bromhexine, ambroxol, $\mathrm{N}$-acetylcysteine, $\mathrm{S}$-carboxymethylcysteine and hypertonic saline in patients, although controversy still exists.

\section{Frusemide}

Frusemide is a diuretic which is also prescribed in asthmatic patients to inhibit the bronchoconstriction induced by allergens, for instance. A single inhalation of nebulized frusemide $(40 \mathrm{mg}$ ) did not affect lung MCC in healthy subjects as well as in stable, mild asthmatics [142]. To the best of the authors' knowledge, no other study is available concerning the effects of frusemide on MCC. 


\section{Antibiotics}

Since patients with chest disorders frequently suffer from respiratory tract infections or even pneumonia, antibiotics are frequently prescribed. Because the retention of mucus is involved in the pathogenesis of both pathological conditions, it seems important to know the influence of antibiotics on MCC. No direct evidence on the influence of antibiotic therapy on human lung MCC is to be found. SCADDING et al. [143], however, showed that the nasal CBF was significantly increased after 3 months of orally administered antibiotic therapy in patients with chronic rhinosinusitis. VINTHER and ELBRøND [144] found no differences in nasal mucociliary function, as measured by the saccharin/sky blue technique, before, during and after penicillin treatment (1 million IU phenoxymethylpenicillin.day ${ }^{-1}$ in tablet form) in healthy subjects.

\section{Anaesthesia}

LiChTiGer et al. [145] studied the influence of intubation, premedication and humidification used for a routine surgical procedure on the TMV in 14 anaesthetized females undergoing gynaecological surgery. All the subjects were nonsmokers with no prior history of pulmonary disease or bronchitis. They noted that $30 \mathrm{~min}$ after halothane-nitrous oxide anaesthesia, the TMV was significantly reduced compared to values observed immediately following intubation. This decrease continued until little or no motion was seen at $90 \mathrm{~min}$. In nine patients, movement of tracheal mucus had completely stopped. In all cases, after 90 min of anaesthesia the trachea was characterized by excessive secretion, redness and oedema. The authors suggested that the depression of such an important host defence mechanism may predispose to postoperative complications due to the increased retention of secretions. This may become more important in patients who already have chronic retention of secretions and/or chronic inflammation. SHELLY [146] points out that ventilation with dry gases may result in heat and moisture loss in the respiratory tract where endotracheal intubation already bypasses the area that normally warms and humidifies inspired gasses. This may lead to dehydratation of the respiratory epithelium with a subsequently impaired mucociliary function. Adequate humidification of the inspired gases is thus necessary.

O'CALlaghan et al. [147] reported that the CBF decreased significantly after in vitro exposure to halothane $(2 \%)$ for $1 \mathrm{~h}$ compared to air in nasal ciliary samples from healthy, term, newborn infants. Similarly, different concentrations of halothane, enflurane and isoflurane are found to depress the $\mathrm{CBF}$ of human nasal epithelium significantly [148, 149].

RUBIN et al. [150] examined the influence of general anaesthesia (different anaesthetic agents and different durations of anaesthesia) on the rigidity (vector sum of viscosity and elasticity), viscoelasticity, spinnability and the percentage of solid composition of respiratory mucus as well as its transport rate on the mucus-depleted frog palate. The respiratory mucus was collected from the endotracheal tube in 25 humans undergoing elective surgery who had no clinical evidence of lung disease. These properties were not significantly different from respira- tory mucus collected from awake volunteers using the bronchoscopy brush collection technique.

In conclusion, anaesthesia has a detrimental effect on lung MCC. A decrease in CBF might possibly lead to these alterations in the functioning of the mucociliary transport system. The fact that mucus collected from patients undergoing surgery is transported at the same speed on the frog palate as mucus collected from awake volunteers supports this view. No changes in sputum rheological properties were observed after anaesthesia, although moisture loss occurs in the airways due to the intubation and the ventilation with dry gases.

\section{Benzodiazepines}

Benzodiazepines are known to have a hypnotic, sedetative as well as anxiolytic action. Temazepam $(10 \mathrm{mg})$ reduced MCC significantly during the first $3 \mathrm{~h}$ after drug ingestion in eight healthy volunteers [151]. Temazepam should thus be prescribed with caution in patients with an already impaired MCC mechanism. Further studies regarding this topic are necessary.

\section{Conclusions}

In conclusion, amiloride and UTP are found either not to alter or to increase MCC. Moreover, amiloride is reported to improve CC. The clinical benefit of administering amiloride to patients is still under discussion. Cholinergics are noted to increase MCC, but are not used therapeutically since they provoke bronchoconstriction. Within anticholinergic medication, tertiary ammonium compounds are reported to decrease MCC, while quaternary ammonium compounds are reported to have either no effect or a stimulatory effect on this process. Caution is still required when administering quaternary ammonium compounds to patients, since ipratropium bromide has been shown to decrease CC. MCC seems to remain unchanged or to increase after treatment with adrenergic agonists. Additionally, a trend towards an improved CC was observed. Conversely, adrenergic antagonists are claimed not to alter MCC. Methylxanthines are suspected to increase MCC, as are corticosteroids in some patients. rhDNase may augment the mucociliary transport rate, although the opposite is suggested to occur when its dosage is too high. Additionally, the effectiveness of coughing is increased. The clinical benefits of rhDNase are well documented. Sodium cromoglycate has been shown to reverse the reduction in tracheal mucus velocity after antigen challenge in asthmatic patients. The administration of aspirin decreases MCC while surfactant is suspected to improve the MCC functioning. From the group of mucolytics and expectorants, hypertonic saline, neutral saline as well as water aerosol increase MCC. Conversely, guaifenesin, $S$-carboxymethylcysteine or sodium 2-mercapto-ethane sulphonate do not significantly alter the functioning of the mucociliary apparatus. Bromhexine and its derivate ambroxol, as well as $N$-acetylcysteine, either do not alter or improve MCC. Surprisingly, bromhexine, ambroxol or neutral saline are found not to alter CC. However, treatment with bromhexine, ambroxol, $N$-acetylcysteine, $S$-carboxymethylcysteine or hypertonic saline may cause clinical improvement in patients, 
although controversy remains. No indications for an improved lung function or an increased subjective wellbeing of the patient are found after treatment with sodium 2-mercapto-ethane sulphonate. Frusemide does not alter MCC. Indirect evidence indicates that the administration of antibiotics does not depress the functioning of the mucociliary apparatus. Anaesthesia is known to impair MCC, and benzodiazepines have been shown to decrease MCC. These findings are, however, sometimes based on only one or a few studies. Thus, further research is necessary to confirm these results and to investigate the remaining questions.

As discussed in the present review, many drugs are able to influence lung MCC either positively or negatively, while other agents do not seem to alter this process. Data obtained by several authors regarding the effect of a specific drug on MCC may, however, give different results. Several factors, however, have to be realized before conclusions on the effect of therapeutic agents on MCC can be drawn.

Although there are several diseases reported to have an impaired lung MCC, the underlying mechanism may differ from one illness to another. The structure, movement and coordination of the cilia present in the airways as well as the amount, composition and rheological properties of the periciliary and the mucus layer are all factors which determine the final outcome of MCC. Consequently, a retarded MCC may result from one or more factors being adversely altered by a certain illness. A therapeutic agent enhancing MCC in one disease may therefore exert either no influence, or even a negative one, on MCC in another illness.

The results of treatment with a drug on lung MCC should be interpreted with care if the route of administration is not the same. Drugs administered by aerosol inhalation are deposited directly onto the airway epithelium, whereas oral therapeutic agents, for example, act via the systemic route. The effective dose reaching the airway epithelium may therefore differ considerably between different routes of administration. The drug dose itself is also important. rhDNase, for example, is suspected to increase MCC in CF patients, although it may decrease MCC when the dose is too high. Alternatively, a certain concentration of drug is probably required in order to be effective. In addition to the route of administration and the dosage, the duration of administration of a certain drug is essential when comparing different results. MCC may be differently influenced after a single administration of a therapeutic agent than after its long-term administration.

Regarding the measurement of MCC, the time between the last drug administration and the measurement itself may alter the results, especially in drugs with a short duration of action. There may also be regional differences in MCC due to drug administration. Whole lung clearance may be divided into outer, intermediate and inner lung clearance. TMV measures the speed of the mucociliary transport solely in the trachea. If no significant differences in whole lung MCC are present, it is still possible that regionally significant differences may occur. Additionally, there are a lot of techniques used to measure MCC or its component functions [152] which may lead to discrepant data.

Finally, it is not the effect of the administration of a single drug, but the combination of drugs that is important to establish in order to reach an optimal treatment regime for MCC disorders. To this extent, several therapeutic agents may have a cummulative action in the treatment regime that other agents may not have.

In addition to MCC, cough is also important for the clearance of mucus out of the ciliated airways. Indeed, CC serves as a back-up system when MCC fails [1]. An increased amount of secretion, however, is necessary in order to make voluntary cough effective in the clearance of mucus out of the airways [2]. Since many patients with chest disorders are known to have hypersecretion in the airways, it is important to examine not only the effect of drugs on MCC but also on CC. Surprisingly, few studies have been performed regarding the effect of medication on CC. This is certainly true for mucolytics and expectorants, drugs stated to favour the clearance of mucus out of the airways by coughing. Research must certainly continue in this area.

After reviewing the literature regarding the influence of drugs on mucus clearance, the question arises as to whether the finding of a statistically significant effect of medication on mucociliary clearance or cough clearance is of clinical relevance. Does the administration of a specific drug known to depress the mucus transport increase the risk of, for example, pneumonia? In contrast, is the administration of a therapeutic agent known to increase mucus clearance able to prevent pulmonary infections or slow down lung function deterioration? There are studies reporting the clinical effect of drug administration in patients. Different factors, such as the frequency of infective exacerbations, the changes in lung function, the experience of dyspnoea and the ease of expectoration, are studied. Further research, however, is needed to establish more precisely the clinical benefit of a specific agent in patients and to examine the exact relationship between alterations in mucus transport induced by a certain drug and its clinical impact on patients.

\section{References}

1. Leith DE. Cough. Phys Ther 1968; 48: 439-447.

2. Camner P. Studies on the removal of inhaled particles from the lungs by voluntary coughing. Chest 1981; 6: 824-827.

3. Knowles MR, Olivier K, Noone P, Boucher RC. Pharmacologic modulation of salt and water in the airway epithelium in cystic fibrosis. Am J Respir Crit Care Med 1995; 151: S65-S69.

4. Waltner WE, Boucher RC, Gatzy JT, Knowles MR. Pharmacotherapy of airway disease in cystic fibrosis. Trends Pharmacol Sci 1987; 8: 316-320.

5. Robinson M, Regnis JA, Bailey DL, King M, Bautovich GJ, Bye PTP. Effect of hypertonic saline, amiloride, and cough on mucociliary clearance in patients with cystic fibrosis. Am J Respir Crit Care Med 1996; 153: 15031509.

6. Graham A, Hasani A, Alton EWFW, et al. No added benefit from nebulized amiloride in patients with cystic fibrosis. Eur Respir J 1993; 6: 1243-1248.

7. App EM, King M, Helfesrieder R, Köhler D, Matthys H. Acute and long-term amiloride inhalation in cystic fibrosis lung disease. A rational approach to cystic fibrosis therapy. Am Rev Respir Dis 1990; 141: 605-612.

8. Köhler D, App E, Schmitz-Schumann M, Würtemberger $\mathrm{G}$, Matthys $\mathrm{H}$. Inhalation of amiloride improves the 
mucociliary and the cough clearance in patients with cystic fibrosis. Eur J Respir Dis 1986; 69 (Suppl. 146): 319326.

9. Middleton PG, Geddes DM, Alton EWFW. Effect of amiloride and saline on nasal mucociliary clearance and potential difference in cystic fibrosis and normal subjects. Thorax 1993; 48: 812-816.

10. Curtis LN, Misch DW. Regulation of mucociliary transport. Response of mucous cells to stimulation by amiloride applied to the frog palate in vitro. Am Rev Respir Dis 1984; 129: 816-822.

11. Di Benedetto G, Lopez-Vidriero MT, Carratù L, Clarke SW. Effect of amiloride on human bronchial ciliary activity in vitro. Respiration 1990; 57: 37-39.

12. Di Benedetto G, Lopez-Vidriero MT, Carratù L, Clarke SW. Does amiloride affect ciliary beat frequency? Eur Respir J 1988; 1: Suppl. 2, 312s.

13. Knowles MR, Church NL, Waltner WE, et al. A pilot study of aerosolized amiloride for the treatment of lung disease in cystic fibrosis. N Engl J Med 1990; 322: 11891194.

14. Lethem MI, Dowell ML, Van Scott M, et al. Nucleotide regulation of goblet cells in human airway epithelial explants: normal exocytosis in cystic fibrosis. Am J Respir Cell Mol Biol 1993; 9: 315-322.

15. Merten MD, Breittmayer J-P, Figarella C, Frelin C. ATP and UTP increase secretion of bronchial inhibitor by human tracheal gland cells in culture. Am J Physiol 1993; 265: L479-L484.

16. Lansley AB, Sanderson MJ, Dirksen ER. Control of the beat cycle of respiratory tract cilia by $\mathrm{Ca}^{2+}$ and cAMP. $\mathrm{Am}$ $J$ Physiol 1992; 263: L232-L242.

17. Knowles MR, Clarke LL, Boucher RC. Activation by extracellular nucleotides of chloride secretion in the airway epithelia of patients with cystic fibrosis. $N$ Engl $J$ Med 1991; 325: 533-538.

18. Benali R, Pierrot D, Zahm JM, de Bentzmann S, Puchelle E. Effects of extracellular ATP and UTP on fluid transport by human nasal epithelial cells in culture. Am J Respir Cell Mol Biol 1994; 10: 363-368.

19. Olivier KN, Bennett WD, Hohneker KW, et al. Acute safety and effects on mucociliary clearance of aerosolized uridine $5^{\prime}$-triphosphateamiloride in normal human adults. Am J Respir Crit Care Med 1996; 154: 217-223.

20. Bennett WD, Olivier KN, Zeman KL, Hohneker KW, Boucher RC, Knowles MR. Effect of uridine 5'-triphosphate plus amiloride on mucociliary clearance in adult cystic fibrosis. Am J Respir Crit Care Med 1996; 153: 1796-1801.

21. Salathé M, O'Riordan TG, Wanner A. Mucociliary clearance. In: Crystal RG, West JB, Barnes PJ, Weibel ER, eds. The Lung: Scientific Foundations. Philadelphia, Lippincott-Raven Publishers, 1997; pp. 2295-2308.

22. White MV. Muscarinic receptors in human airways. $J$ Allergy Clin Immunol 1995; 95: 1065-1068.

23. Scheuch G, Philipson K, Falk R, et al. Retention of particles inhaled in boli with and without induced bronchoconstriction. Exp Lung Res 1995; 21: 901-916.

24. Cammer P, Strandberg K, Philipson K. Increased mucociliary transport by cholinergic stimulation. Arch Environ Health 1974; 29: 220-224.

25. Logun C, Mullol J, Rieves D, et al. Use of a monoclonal antibody enzyme-linked immunosorbent assay to measure human respiratory glycoprotein production in vitro. Am J Respir Cell Mol Biol 1991; 5: 71-79.

26. Boat TF, Kleinerman JI. Human respiratory tract secretions. Effect of cholinergic and adrenergic agents on in vitro release of protein and mucous glycoprotein. Chest 1975; 67: 32S-34S.

27. Shelhamer JH, Marom Z, Kaliner M. Immunologic and neuropharmacologic stimulation of mucous glycoprotein release from human airways in vitro. J Clin Invest 1980; 66: $1400-1408$.

28. Rogers DF, Alton EWFW, Dewar A, Lethem MI, Barnes PJ. Impaired stimulus-evoked mucus secretion in cystic fibrosis bronchi. Exp Lung Res 1993; 19: 37-53.

29. Iravani J, Melville GN. Wirkung von Pharmaka und Milieuänderungen auf die Flimmertätigkeit der Atemwege. Respiration 1975; 32: 157-164.

30. Gross NJ, Skorodin MS. Anticholinergic, antimuscarinic bronchodilators. Am Rev Respir Dis 1984; 129: 856-870.

31. Yeates DB, Aspin N, Levison H, Jones MT, Bryan AC. Mucociliary transport rates in man. J Appl Physiol 1975; 39: 487-494.

32. Foster WM, Bergofsky EH, Bohning DE, Lippmann M, Albert RE. Effect of adrenergic agents and their mode of action on mucociliary clearance in man. $J$ Appl Physiol 1976; 41: 146-152.

33. Pavia D, Thomson ML. Inhibition of mucociliary clearance from the human lung by hyoscine. Lancet 1971; 27: 449-450.

34. Iravani J, Melville GN. Ciliary movement following various concentrations of different anticholinergic and adrenergic bronchodilator solutions in animals. Postgrad Med J 1975; 51 (Suppl. 7): 108.

35. Lopez-Vidriero MT, Costello J, Clark TJH, Das I, Keal EE, Reid L. Effect of atropine on sputum production. Thorax 1975; 30: 543-547.

36. Costello JF, Lopez-Vidriero MT, Charman J, Das I, Keal E, Reid L. The effect of atropine sulphate on sputum production. Postgrad Med J 1975; 51 (Suppl. 7): 107.

37. Francis RA, Thomson ML, Pavia D, Douglas RB. Ipratropium bromide: mucociliary clearance rate and airway resistance in normal subjects. Br J Dis Chest 1977; 71: 173-178.

38. Pavia D, Bateman JRM, Sheahan NF, Clarke SW. Effect of ipratropium bromide on mucociliary clearance and pulmonary function in reversible airway obstruction. Thorax 1979; 34: 501-507.

39. Pavia D, Bateman JRM, Sheahan NF, Clarke SW. Clearance of lung secretions in patients with chronic bronchitis: effect of terbutaline and ipratropium bromide aerosols. Eur J Respir Dis 1980; 61: 245-253.

40. Bell JA, Bluestein BM, Danta I, Wanner A. Effect of inhaled ipratropium bromide on tracheal mucociliary transport in bronchial asthma. Mt Sinai J Med 1984; 51: 215-217.

41. Ruffin RE, Wolff RK, Dolovich MB, Rossman CM, Fitzgerald JD, Newhouse MT. Aerosol therapy with Sch 1000: short-term mucociliary clearance in normal and bronchitic subjects and toxicology in normal subjects. Chest 1978; 73: 501-506.

42. Taylor RG, Pavia D, Agnew JE, et al. Effect of four weeks' high dose ipratropium bromide treatment on lung mucociliary clearance. Thorax 1986; 41: 295-300.

43. Puchelle E, Uffholtz H. Sputum viscoelasticity following administration of Sch 1000 MDI. Postgrad Med J 1975; 51 (Suppl. 7): 109.

44. Stresemann E. Total airways resistance (Rt), sputum volume and rheology in patients with chronic bronchitis following treatment with Sch 1000 MDI and placebo. Postgrad Med J 1975; 51 (Suppl. 7): 110.

45. Tamaoki J, Chiyotani A, Tagaya E, Sakai N, Konno K. Effect of long term treatment with oxitropium bromide on 
airway secretion in chronic bronchitis and diffuse panbronchiolitis. Thorax 1994; 49: 545-548.

46. Bennett WD, Chapman WF, Mascarella JM. The acute effect of ipratropium bromide bronchodilator therapy on cough clearance in COPD. Chest 1993; 103: 488-495.

47. Foster WM, Langenback E, Bergofsky EH. Measurement of tracheal and bronchial mucus velocities in man: relation to lung clearance. J Appl Physiol 1980; 48: 965971.

48. Lafortuna CL, Fazio F. Acute effect of inhaled salbutamol on mucociliary clearance in health and chronic bronchitis. Respiration 1984; 45: 111-123.

49. Mortensen J, Lange P, Jorgen N, Groth S. Lung mucociliary clearance. Eur J Nucl Med 1994; 21: 953-961.

50. Groth S, Mortensen J, Lange P, Munch EP, Sorensen PG, Rossing N. Imaging of the airways by bronchoscintigraphy for the study of mucociliary clearance. Thorax 1988; 43: 360-365.

51. Konietzko N, Klopfer M, Adam WE, Matthys H. Die mokociliare Klärfunktion der Lunge unter $\beta$-adrenerger Stimulation. Pneumologie 1975; 152: 203-208.

52. Camner P, Strandberg K, Philipson K. Increased mucociliary transport by adrenergic stimulation. Arch Environ Health 1976; 39: 79-82.

53. Yeates DB, Spektor DM, Pitt BR. Effect of orally administered orciprenaline on tracheobronchial mucociliary clearance. Eur J Respir Dis 1986; 69: 100-108.

54. Spektor DM, Pitt BR, Yeates DB. Changes in regional mucociliary transport in the human lung resulting from systemic beta 2 adrenergic stimulation. Am Rev Respir Dis 1979; 119: 236.

55. Wood RE, Wanner A, Hirsch J, Farrell PM. Tracheal mucociliary transport in patients with cystic fibrosis and its stimulation by terbutaline. Am Rev Respir Dis 1975; 111: 733-738.

56. Isawa $\mathrm{T}$, Teshima $\mathrm{T}$, Hirano $\mathrm{T}$, et al. Does a b2-stimulator really facilitate mucociliary transport in the human lungs in vivo? A study with procaterol. Am Rev Respir Dis 1990; 141: 715-720.

57. Olivieri D, Marsico SA, Illiano A, Del Donno M. In vivo measurement of drug effect on mucociliary transport. Eur J Respir Dis 1983; 64 (Suppl. 128): 551-553.

58. Mossberg B, Strandberg K, Philipson K, Camner P. Tracheobronchial clearance and beta-adrenoceptor stimulation in patients with chronic bronchitis. Scand J Respir Dis 1976; 57: 281-289.

59. Sackner MA, Yergin BM, Brito M, Januszkiewicz A. Effect of adrenergic agonists on tracheal mucous velocity. Bull Eur Physiopath Resp 1979; 15: 505-511.

60. Matthys H, Daikeler G, Krauss B, Vastag E. Action of tulobuterol and fenoterol on the mucociliary clearance. Respiration 1987; 51: 105-112.

61. Weiss T, Dorow P, Felix R. Effects of a beta adrenergic drug and a secretolytic agent on regional mucociliary clearance in patients with COLD. Chest 1981; 80 (Suppl. 6): $881-885$.

62. Sadoul P, Puchelle E, Zahm J, Jacquot J, Aug F, Polu JM. Effect of terbutaline on mucociliary transport and sputum properties in chronic bronchitis. Chest 1981; 80 (Suppl. 6): 885-889.

63. Foster WM, Langenback E, Bergofsky EH. Lung clearance and central airway transport of mucus in asymptomatic smokers and age-matched healthy subjects: comparison of control and $\beta_{2}$-adrenergic clearance. $A m$ Rev Respir Dis 1979; 119: 309.

64. Foster WM, Langenback EG, Bergofsky EH. Disassociation in the mucociliary function of central and peri- pheral airways of asymptomatic smokers. Am Rev Respir Dis 1985; 132: 633-639.

65. Mortensen J, Groth S, Lange P, Rossing N. Bronchoscintigraphic visualization of the acute effect of tobacco exposure and terbutaline on mucociliary clearance in smokers. Eur Respir J 1989; 2: 721-726.

66. Felix R, Hedde JP, Zwicker HJ, Winkler C. Mukoziliäre Klärfunktion unter $\beta$-adrenerger Stimulation mit Fenoterol. Prax Pneumol 1978; 32: 777-782.

67. Mossberg B, Strandberg K, Philipson K, Camner P. Tracheobronchial clearance in bronchial asthma: response to beta-adrenoceptor stimulation. Scand J Respir Dis 1976; 57: 119-128.

68. Bateman JRM, Pavia D, Sheahan NF, Newman SP, Clarke SW. Effects of terbutaline sulphate aerosol on bronchodilator response and lung mucociliary clearance in patients with mild stable asthma. Br J Clin Pharmac 1983; 15: 695-700.

69. Hasani A, Agnew JE, Pavia D, Vora H, Clarke SW. Effect of oral bronchodilators on lung mucociliary clearance during sleep in patients with asthma. Thorax 1993; 48: 287-289.

70. Mortensen J, Hansen A, Falk M, Nielsen IK, Groth S. Reduced effect of inhaled $\beta_{2}$-adrenergic agonists on lung mucociliary clearance in patients with cystic fibrosis. Chest 1993; 103: 805-811.

71. Mortensen J, Engel AM, Milman N, Nielsen F, Faurshou P. Inhaled terbutaline improves mucociliary clearance in patients with bronchiectasis. Eur Respir J 1992; 5: Suppl. $15,385 \mathrm{~s}$.

72. Devalia JL, Sapsford RJ, Rusznak C, Toumbis MJ, Davies RJ. The effects of salmeterol and salbutamol on ciliary beat frequency of cultured human bronchial epithelial cells in vitro. Pulm Pharmacol 1992; 5: 257-263.

73. Phipps RJ, Williams IP, Richardson PS, Pell J, Pack RJ, Wright N. Sympathomimetic drugs stimulate the output of secretory glycoproteins from human bronchi in vitro. Clin Sci 1982; 63: 23-28.

74. Bateman JRM, Lennard-Jones AM, Pavia D, Clarke SW. Lung mucociliary clearance in normal subjects during selective and non-selective $\beta$-adrenoceptor blockade. Clin Sci 1980; 58: 6p.

75. Cotromanes E, Gerrity TR, Garrard CS, et al. Aerosol penetration and mucociliary transport in the healthy human lung: effect of low serum theophylline levels. Chest 1985; 88: 194-200.

76. Sutton PP, Pavia D, Bateman JRM, Clarke SW. The effect of oral aminophylline on lung mucociliary clearance in man. Chest 1981; 80 (Suppl. 6): 889-892.

77. Todisco T, Baglioni S, Amir E, Palumbo R. Effect of bamiphylline on tracheobronchial mucus clearance in subjects with smokers' simple chronic bronchitis. Respiration 1995; 62: 16-20.

78. Pearson MG, Ahmad D, Chamberlain MJ, Morgan WKC, Vinitski S. Aminophylline and mucociliary clearance in patients with irreversible airflow limitation. $B r J$ Clin Pharmacol 1985; 20: 688-690.

79. Welsh MJ, Widdicombe JH, Nadel JA. Fluid transport across the canine tracheal epithelium. J Appl Physiol 1980; 49: 905-909.

80. Whimster WF, Reid L. The influence of dibutyryl cyclic adenosine monophosphate and other substances on human bronchial mucous gland discharge. Exp Mol Pathol l 973; 18: 234-240.

81. Agnew JE, Bateman JRM, Pavia D, Clarke SW. Peripheral airways mucus clearance in stable asthma is 
improved by oral corticosteroid therapy. Bull Eur Physiopath Resp 1984; 20: 295-301.

82. Fazio F, Lafortuna CL. Beclomethasone dipropionate does not affect mucociliary clearance in patients with chronic obstructive lung disease. Respiration 1986; 50: $62-65$.

83. Hodson ME, Batten JC, Clarke SW, Gregg I. Beclomathasone dipropionate aerosol in asthma. Am Rev Respir Dis 1974; 110: 403-408.

84. Marom Z, Shelhamer J, Alling D, Kaliner M. The effects of corticosteroids on mucous glycoprotein secretion from human airways in vitro. Am Rev Respir Dis 1984; 129: $62-65$.

85. Lundgren JD, Kaliner MA, Shelhamer JH. Mechanisms by which glucocorticosteroids inhibit secretion of mucus in asthmatic airways. Am Rev Respir Dis 1990; 141: S52S58.

86. Agnew JE, Bateman JRM, Sheahan NF, Lennard-Jones AM, Pavia D, Clarke SW. Effect of oral corticosteroids on mucus clearance by cough and mucociliary transport in stable asthma. Bull Eur Physiopath Respir 1983; 19: 3741.

87. Creeth JM. Constituents of mucus and their separation. Br Med Bull 1978; 34: 17-24.

88. Lethem MI, James SL, Marriott C, Burke JF. The origin of DNA associated with mucus glycoproteins in cystic fibrosis sputum. Eur Respir J 1990; 3: 19-23.

89. Zahm J, Girod de Bentzmann S, Deneuville E, et al. Dose-dependent in vitro effect of recombinant human DNAse on rheological and transport properties of cystic fibrosis respiratory mucus. Eur Respir J 1995; 8: 381-386.

90. Sinicropi DV, Williams M, Prince WS, et al. Sputum pharmacodynamics and pharmacokinetics of recombinant human DNase I in cystic fibrosis. Am Rev Respir Dis 1994; 149: A671.

91. Shak S, Capon DJ, Hellmiss R, Marsters SA, Baker CL. Recombinant human DNase I reduces the viscosity of cystic fibrosis sputum. Proc Natl Acad Sci USA 1990; 87: 9188-9192.

92. Puchelle E, Zahm JM. Effet de la rhDNase sur les propriétés rhéologiques et la capacité de transport du mucus dans la mucoviscidose. Arch PÕdiatr 1995; 2: 670-673.

93. Rubin BK, Ramirez OK, Baharav AL. The physical and transport properties of $\mathrm{CF}$ sputum after treatment with rhDNase. Pediatr Pulmonol 1993; 16 (Suppl. 9): A251.

94. Tomkiewicz RP, Shak S, King M. Effects of rhDNase on cystic fibrosis sputum viscoelasticity in vitro. Pediatr Pulmonol 1993; 16 (Suppl. 9): A251.

95. Shah PL, Ingham S, Marriott C, Scott SF, Hodson ME. The in vitro effects of two novel drugs on the rheology of cystic fibrosis and brochiectasis sputum. Eur Respir $J$ 1994; 7: Suppl. 18, 12s.

96. Zahm JM, de Bentzmann S, Deneuville E, et al. Recombinant human DNase I improves the transport of cystic fibrosis respiratory mucus ex vivo. Pediatr Pulmonol 1993; 16 (Suppl. 9): A250.

97. Shah PL, Scott S, Marriott C, Hodson ME. A preliminary report on in vivo reduction of sputum viscoelasticity in cystic fibrosis patients treated with aerosolised recombinant human DNase I. Am Rev Respir Dis 1994; 149: A671.

98. Dasgupta B, King M. Reduction in viscoelasticity in cystic fibrosis sputum in vitro using combined treatment with Nacystelyn and rhDNase. Pediatr Pulmonol 1996; 22: 161-166.

99. Wills PJ, Wodehouse T, Corkery K, Mallon K, Wilson R, Cole PJ. Short-term recombinant human DNase in bronchiectasis. Effect on clinical state and in vitro sputum transportability. Am J Respir Crit Care Med 1996; 154: 413-417.

100. King M, Dasgupta B, Tomkiewicz RP, Brown NE. Rheology of cystic fibrosis sputum after in vitro treatment with hypertonic saline alone and in combination with recombinant human deoxyribonuclease I. Am J Respir Crit Care Med 1997; 156: 173-177.

101. Shah PL, Scott SF, Knight RA, Marriott C, Ranasinha C, Hodson ME. In vivo effects of recombinant human DNase I on sputum in patients with cystic fibrosis. Thorax 1996; 51: 119-125.

102. King M, Brock G, Lundell C. Clearance of mucus by simulated cough. J Appl Physiol 1985; 58: 1776-1782.

103. Ramsey BW, Astley SJ, Aitken ML, et al. Efficacy and safety of short-term administration of aerosolized recombinant human deoxyribonuclease in patients with cystic fibrosis. Am Rev Respir Dis 1993; 148: 145-151.

104. Hodson ME. Aerosolized dornase alfa (rhDNase) for therapy of cystic fibrosis. Am J Respir Crit Care Med 995; 151: S70-S74.

105. Shak S. Aerosolized recombinant human DNase I for the treatment of cystic fibrosis. Chest 1995; 107: 65S-70S.

106. Pavia D, Lopez-Vidriero MT, Clarke SW. Mediators and mucociliary clearance in asthma. Bull Eur Physiopath Respir 1987; 23 (Suppl. 10P): 89s-94s.

107. Mezey RJ, Cohn MA, Fernandez RJ, Januszkiewicz AT, Wanner A. Mucociliary transport in allergic patients with antigen-induced bronchospasm. Am Rev Respir Dis 1978; 118: 677-684

108. Norris AA, Alton EWFW. Chloride transport and the action of sodium cromoglycate and nedocromil sodium in asthma. Clin Exp Allergy 1996; 26: 250-253.

109. Alton EWFW, Kingsleigh-Smith DJ, Munkonge FM, et al. Asthma prophylaxis agents alter the function of an airway epithelial choride channel. Am J Respir Cell Mol Biol 1996; 14: 380-387.

110. Gerrity TR, Cotromanes E, Garrard CS, Yeates DB, Lourenço RV. The effect of aspirin on lung mucociliary clearance. N Engl J Med 1983; 308: 139-141.

111. Brown DL, Pattishall EN. Other uses of surfactant. Clin Perinatol 1993; 20: 761-789.

112. Outzen K-E, Svane-Knudsen V. Effect of surface-active substance on nasal mucociliary clearance time: a comparison of saccharin clearance time before and after the use of surface-active substance. Rhinology 1992; 31: 155-157.

113. De Sanctis GT, Tomkiewicz RP, Rubin BK, Schürch S, King M. Exogenous surfactant enhances mucociliary clearance in the anaesthetized dog. Eur Respir J 1994; 7 : 1616-1621.

114. Sisson JH, Yonkers AJ, Waldman RH. Effects of guaifenesin on nasal mucociliary clearance and ciliary beat frequency in healthy volunteers. Chest 1995; 107 : 747-751.

115. Yeates DB, Cohen VR, Davis AL, Albert RE, Waillant J, Lippman M. Effect of glyceryl guaiacolate on bronchial clearance in patients with chronic bronchitis. Am Rev Respir Dis 1977; 115 (Suppl.): 182.

116. Goodman RM, Yergin BM, Sackner MA. Effects of $S$ carboxymethylcysteine on tracheal mucus velocity. Chest 1978; 74: 615-618.

117. Thomson ML, Pavia D, Jones CJ, McQuiston TAC. No demonstrable effect of $S$-carboxymethylcysteine on clearance of secretions from the human lung. Thorax 1975; 30: 669-673.

118. Edwards GF, Steel AK, Scott JK, Jordan JW. $S$ carboxymethylcysteine in the fluidification of sputum 
and treatment of chronic airway obstruction. Chest 1976; 70: 506-513.

119. Todisco T, Polidori R, Rossi F, et al. Effect of $N$-acetylcysteine in subjects with slow pulmonary mucociliary clearance. Eur J Respir Dis 1985; 66 (Suppl. 139): 136141.

120. Olivieri D, Marsico SA, Del Donno M. Improvement of mucociliary transport in smokers by mucolytics. Eur $J$ Respir Dis 1985; 66 (Suppl. 139): 142-145.

121. Millar AB, Pavia D, Agnew JE, Lopez-Vidriero MT, Lauque D, Clarke SW. Effect of oral $N$-acetylcysteine on mucus clearance. Br J Dis Chest 1985; 79: 262-266.

122. Puchelle E, Girard F, Zahm JM. Rhéologie des sécrétions bronchiques et transport mucociliaire. Bull Eur Physiopath Resp 1976; 12: 771-779.

123. Aylward M, Maddock J, Dewland P. Clinical evaluation of acetylcysteine in the treatment of patients with chronic obstructive bronchitis: a balanced double-blind trial with placebo control. Eur J Respir Dis 1980; 61 (Suppl. 111): 81-89.

124. Jackson IM, Barnes J, Cooksey P. Efficacy and tolerability of oral acetylcysteine (Fabrol) in chronic bronchitis: a double-blind placebo controlled study. J Int Med Res 1984; 12: 198-206.

125. Dueholm M, Nielsen C, Thorshauge $\mathrm{H}$, et al. $N$ acetylcysteine by metered dose inhaler in the treatment of chronic bronchitis: a multi-centre study. Respir Med 1992; 86: 89-92.

126. Boman G, Bäckner U, Larsson S, Melander B, Wahlander L. Oral acetylcysteine reduces exacerbation rate in chronic bronchitis: report of a trial organized by the Swedish Society for Pulmonary Diseases. Eur J Respir Dis 1983; 64: 405-415.

127. Aurnhammer W, Konietzko N, Matthys H. Problems in evaluating the effect of secretolytic agents on the mucociliary system by means of radioactive particles. Respiration 1977; 34: 92-99.

128. Mossberg B, Philipson K, Strandberg K, Camner P. Clearance by voluntary coughing and its relationship to subjective assessment and effect of intravenous bromhexine. Eur J Respir Dis 1981; 62: 173-179.

129. Lal S, Bhalla KK. A controlled trial of bromhexine ("Bisolvon") in out-patients with chronic bronchitis. Curr Med Res Opin 1975; 3: 63-67.

130. Hargrave SA, Palmer KNV, Makin EJB. Effect of bromhexine on the incidence of postoperative bronchopneumonia after abdominal surgery. Br J Dis Chest 1975; 69: 195-198.

131. Lusuardi M, Capelli A, Carli S, Tacconi MT, Salmona M, Donner CF. Role of surfactant in chronic obstructive pulmonary disease: therapeutic implications. Respiration 1992; 59 (Suppl. 1): 28-32.

132. Dirksen H, Hermansen F, Groth S, Molgaard F. Mucociliary clearance in early simple chronic bronchitis. Eur $J$ Respir Dis 1987; 71 (Suppl. 153): 145-149.

133. Ericsson CH, Juhász J, Mossberg B, Philipson K, Svartengren M, Camner P. Influence of ambroxol on tracheobronchial clearance in simple chronic bronchitis. Eur $J$ Respir Dis 1987; 70: 163-170.

134. Germouty J, Jirou-Najou JL. Clinical efficacy of ambroxol in the treatment of bronchial stasis. Clinical trial in
120 patients at two different doses. Respiration 1997; 51 (Suppl. 1): 37-41.

135. Würtemberger G, Michaelis K, Matthys H. Additive Wirkung von Theophyllin und Ambroxol auf die bronchiale Clearance? Prax Klin Pneumol 1988; 42: 300-303.

136. Ericsson CH, Juhász J, Jönsson E, Mossberg B. Ambroxol therapy in simple chronic bronchitis: effects on subjective symptoms and ventilatory function. Eur $J$ Respir Dis 1986; 69: 248-255.

137. Clarke SW, Lopez-Vidriero MT, Pavia D, Thomson ML. The effect of sodium 2-mercaptoethane sulphonate and hypertonic saline aerosols on bronchial clearance in chronic bronchitis. Br J Clin Pharmacol 1979; 7: 39-44.

138. Daviskas E, Anderson SD, Gonda I, et al. Inhalation of hypertonic saline aerosol enhances mucociliary clearance in asthmatic and healthy subjects. Eur Respir J 1996; 9: 725-732.

139. Pavia D, Thomson ML, Clarke SW. Enhanced clearance of secretions from the human lung after the administration of hypertonic saline aerosol. Am Rev Respir Dis 1978; 117: 199-203.

140. Wood RE, Horowitz JG, Mancini N. Effect of saline aerosol on tracheal mucociliary transport in normal subjects and patients with cystic fibrosis. Am Rev Respir Dis 1977; 115 (Suppl.): 295.

141. Lippmann M, Albert RE, Yeates DB, Berger JM, Foster WM, Bohning DE. Factors affecting tracheobronchial mucociliary transport. Inhaled Part 1975; 4: 305-319.

142. Hasani A, Pavia D, Spiteri MA, et al. Inhaled frusemide does not affect lung mucociliary clearance in healthy and asthmatic subjects. Eur Respir J 1994; 7: 1497-1500.

143. Scadding GK, Lund VJ, Darby YC. The effect of longterm antibiotic therapy upon ciliary beat frequency in chronic rhinosinusitis. J Laryngol Otol 1995; 109: 24-26.

144. Vinther B, Elbrønd O. Nasal mucociliary function during penicillin treatment. Acta Otolaryngol 1978; 86: 132-134.

145. Lichtiger M, Landa JF, Hirsch JA. Velocity of tracheal mucus in anesthetized women undergoing gynecologic surgery. Anesthesiology 1975; 42: 753-756.

146. Shelly MP. Effects of dry inspired gases in anaesthesia. $\mathrm{Br}$ J Hosp Med 1988; 40: 81.

147. O'Callaghan C, Atherton M, Karim K, et al. The effect of halothane on neonatal ciliary beat frequency. $J$ Paediatr Child Health 1994; 30: 429-431.

148. Raphael JH, Selwyn DA, Mottram SD, Langton JA, $\mathrm{O}^{\prime}$ Callaghan C. Effects of 3 MAC of halothane, enflurane and isoflurane on cilia beat frequency of human nasal epithelium in vitro. Br J Anaesth 1996; 76: 116-121.

149. Gyi A, O'Callaghan C, Langton JA. Effect of halothane on cilia beat frequency of ciliated human respiratory epithelium in vitro. Br J Anaesth 1994; 73: 507-510.

150. Rubin BK, Finegan B, Ramirez O, King M. General anaesthesia does not alter the viscoelastic or transport properties of human respiratory mucus. Chest 1990; 98: 101-104.

151. Hasani A, Spiteri MA, Pavia D, Lopez-Vidriero MT, Agnew JE, Clarke SW. Effect of temazepam on tracheobronchial mucus clearance. Thorax 1992; 47: 298-300.

152. Braga PC, Allegra L. Methods in Bronchial Mucology. New York, Raven Press, 1988. 